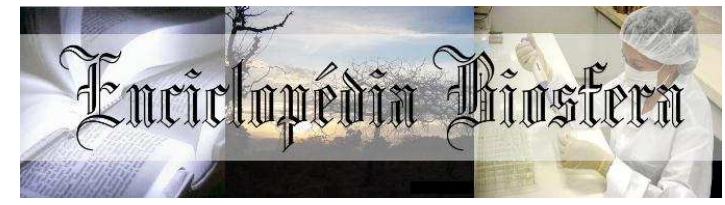

\title{
CARACTERIZAÇÃO HIDROGEOMORFOLÓGICA DAS PAISAGENS COMPONENTES DA BACIA HIDROGRÁFICA DO RIO TAPAJÓS
}

Ivinny Barros de Araujo ${ }^{1}$, Aline Maria Meiguins de Lima ${ }^{2}$, Cleber Assis dos Santos ${ }^{3}$

${ }^{1}$ Acadêmica do curso de Geologia da Universidade Federal do Pará, Laboratório de

Estudos e Modelagens Hidroambientais (LEMHA), Belém - PA, Brasil

(ivinny_barros@hotmail.com)

${ }^{2}$ Professora Doutora da Universidade Federal do Pará, Programa de Pós

Graduação em Ciências Ambientais, Belém - PA, Brasil

${ }^{3}$ Acadêmico do curso de Meteorologia da Universidade Federal do Pará, Laboratório

de Estudos e Modelagens Hidroambientais (LEMHA), Belém - PA, Brasil

Recebido em: 08/09/2015 - Aprovado em: 14/11/2015 - Publicado em: 01/12/2015

DOI: http://dx.doi.org/10.18677/Enciclopedia_Biosfera_2015_046

\begin{abstract}
RESUMO
A compreensão da inter-relação entre a dinâmica hidrológica e a geomorfologia favorece a melhor compreensão da dinâmica da paisagem no contexto das bacias hidrográficas. Dessa forma, este trabalho teve como objetivo caracterizar e analisar as Unidades Hidrogeomorfológicas (UHs) da bacia do Tapajós, a fim de propor um modelo do comportamento das diferentes formas de relevo frente à dinâmica hidrológica da área de estudo. A metodologia desenvolvida visou identificar as UHs a partir da análise integrada entre: geoformas do relevo, tomando como base as unidades geológicas regionais, os diferentes padrões de drenagem e os parâmetros morfométricos. Estes dados, junto com as características hidroclimatológicas, possibilitaram a maior compreensão da interação água vs. relevo na região. A sul, predominantemente, a bacia do Tapajós apresenta regiões mais favoráveis aos processos de modificação do relevo, caracterizando também uma área com maior potencial ao acúmulo e transporte de sedimentos inconsolidados. Na região do médio-baixo curso do rio Tapajós, os processos de modificação na paisagem são menos intensos; no entanto, predomina o acúmulo de materiais inconsolidados em decorrência dos sedimentos provenientes das regiões mais altas da bacia, bem como ao transporte mais rápido dos mesmos devido a maior vazão dos rios em direção a foz do rio Tapajós e a maior média pluviométrica anual na região.
\end{abstract}

PALAVRAS-CHAVE: Bacia hidrográfica, dinâmica hidrológica, geomorfologia, hidrogeomorfologia, paisagem

\section{HYDROGEOMORPHOLOGY CHARACTERIZATION OF LANDSCAPE IN THE TAPAJÓS RIVER WATERSHED}

\begin{abstract}
Understanding the interrelationship between the hydrological dynamics and geomorphology enables a better understanding of landscape dynamics, showing the importance of studying hydrogeomorphologys process in watersheds. Thus, this
\end{abstract}


study aims to characterize and analyze the Hydrogeomorphologys Units in Tapajós basin, in order to propose a model of the behavior of different forms of relief against the hydrological dynamics of the study area. The methodology aims to identify the units from the integrated analysis between landforms relief, based on regional geological, different drainage patterns and morphometric parameters. These data, along with the hydroclimatology characteristics in this area, enable greater understanding of the interaction water and relief in the region. The southern, predominantly, the basin of Tapajós has more favorable regions to relief modification processes, also featuring an area with the greatest potential to accumulation and transport of unconsolidated sediments. In the region of the middle-lower course of the Tapajós River, the landscape modification processes are less intense. However, the predominant accumulation of unconsolidated materials because of sediments from the higher regions of the basin, as well as faster transport thereof due to higher river flows toward the mouth of the Tapajos river and the highest average annual rainfall in the region.

KEYWORDS: Geomorphology, hydrogeomorphology, hydrological dynamics, landscape, watershed

\section{INTRODUÇÃO}

A Política Nacional de Proteção e Defesa Civil (PNPDEC), nº 12.608, tem como uma de suas diretrizes a adoção de bacias hidrográficas como unidade de análise e planejamento em busca da identificação e adoção de ações preventivas à ocorrência de desastres naturais ou induzidos pelos processos de ação antrópica. Como os rios constituem principais definidores da paisagem, pois apresentam relativa homogeneidade quanto aos processos de dinâmica superficial (FISHER et al. 2007; WHITTAKER et al. 2010; ATTAL et al. 2015), nota-se a importância da compreensão do comportamento hidrológico nas mesmas, bem como a interação com os demais componentes do meio físico. Dentro desse contexto, vale ressaltar a importância do conhecimento geomorfológico de uma região, pois, como mostra GIRÃO \& CORRÊA (2004), este auxilia no planejamento para implantação de diferentes projetos.

Como mostram HUGGETT (2005) e LANA \& CASTRO (2012), a geomorfologia diz respeito ao estudo das formas presentes na superfície terrestre, preocupando-se tanto com a descrição do relevo quanto com a análise dos processos dinâmicos que condicionaram sua gênese e evolução; onde a taxa dos processos geomorfológicos pode mudar com o tempo, tal que algumas feições foram produzidas sob diferentes condições no passado, tendo uma longa história de formação, e sua atual forma nem sempre está relacionada com a dinâmica recente dos processos. Dessa forma, como a dinâmica hidrológica apresenta uma importância expressiva quanto aos processos de estruturação das diferentes formas de relevo, SCHEIDEGGER (1973) propôs o termo Hidrogeomorfologia. A partir disso, BABAR (2011) e JADHAV \& BABAR (2014) consideram a decomposição do termo em: "hidro" incorporando a ação das águas superficiais e subterrâneas; "geo" relativo à terra; e "morfologia" que traduz as características superficiais nas formas da paisagem.

GOERL et al. (2012) definem o estudo da Hidrogeomorfologia como uma ciência que busca compreender como os processos hidrológicos contribuem para a formação e evolução da paisagem e ainda como as formas de relevo condicionam ou controlam os processos hidrológicos em diferentes escalas temporais e espaciais, ou seja, compreender como a dinâmica hidrológica de uma região modifica o relevo e de que forma essa alteração influenciará no comportamento da rede de drenagem (figura 1 ). 
A Região Hidrográfica Amazônica (RHA), com 3.869 .953 km², detém 73,6\% de águas superficiais acessíveis do país, a contribuição para o ciclo hidrológico representa um percentual significativo da recepção pluviométrica $(1.075 \mathrm{~mm}-46 \%$ a $1.164 \mathrm{~mm}$ - 54\%) com vazões que chegam a $131.947 \mathrm{~m}^{3} / \mathrm{s}$ (MACHADO \& PACHECO, 2010). Inserido no contexto da RHA, a Bacia Hidrográfica do Tapajós (BHT) apresenta uma variabilidade na paisagem, gradando de áreas topográficas mais elevadas em terrenos sedimentares até regiões mais baixas em terrenos cristalinos do Cratón Amazônico e sedimentares da Bacia do Amazonas.

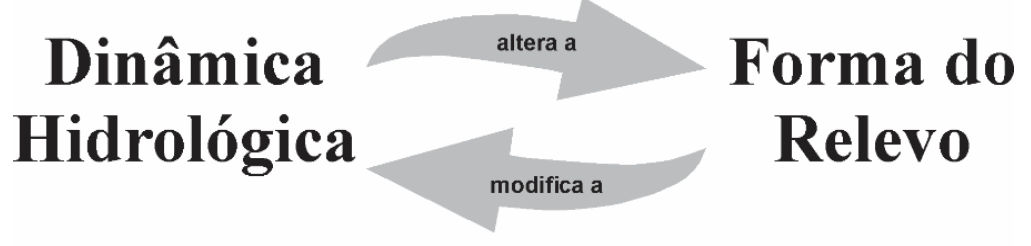

FIGURA 1. Inter-relação entre a dinâmica hidrológica e as formas do relevo. Fonte: Autores

Neste contexto, a partir dos métodos de levantamento e caracterização do meio físico por meio de sensores remotos, já que estas ferramentas são de suma importância para o zoneamento das feições de relevo (LOLLO et al. 2015), através do uso do Modelo Digital de Elevação (MDE), este trabalho objetivou a caracterização e a analise das Unidades Hidrogeomorfológicas (UHs) da bacia do Tapajós a fim de propor um modelo regional do comportamento dos diferentes conjuntos de formas de relevo frente à dinâmica hidrológica, auxiliando assim na compreensão da paisagem da mesma, bem como no controle de problemas ambientais associados, principalmente quanto a ação de processos deposicionais e erosivos na bacia.

\section{MATERIAL E MÉTODOS}

Com uma área de, aproximadamente, $492 \mathrm{mil} \mathrm{km}^{2}$ a BHT abrange os estados do Pará, Mato Grosso e o Amazonas, estando entre as latitudes 0294'38"S e $1467^{\prime} 38,4^{\prime \prime}$ 'S e longitudes 53\%9'34"W e 60' '42"W, c omo mostra a figura 2. Para a elaboração deste trabalho foram utilizados as bases de dados vetoriais em SIG (Sistemas de Informação Geográfica) elaborado pela CPRM (Serviço Geológico do Brasil) para o mapa de geologia, na escala 1: 1.000.000, disponível no GEOBANK; pelo IBGE para o mapa geomorfológico, na escala de 1:250.000, no Projeto de Sistematização das Informações sobre Recursos Naturais no recorte da Amazônia Legal; bem como os dados hidrológicos da ANA (Agência Nacional de Águas), na escala de 1:250.000. 

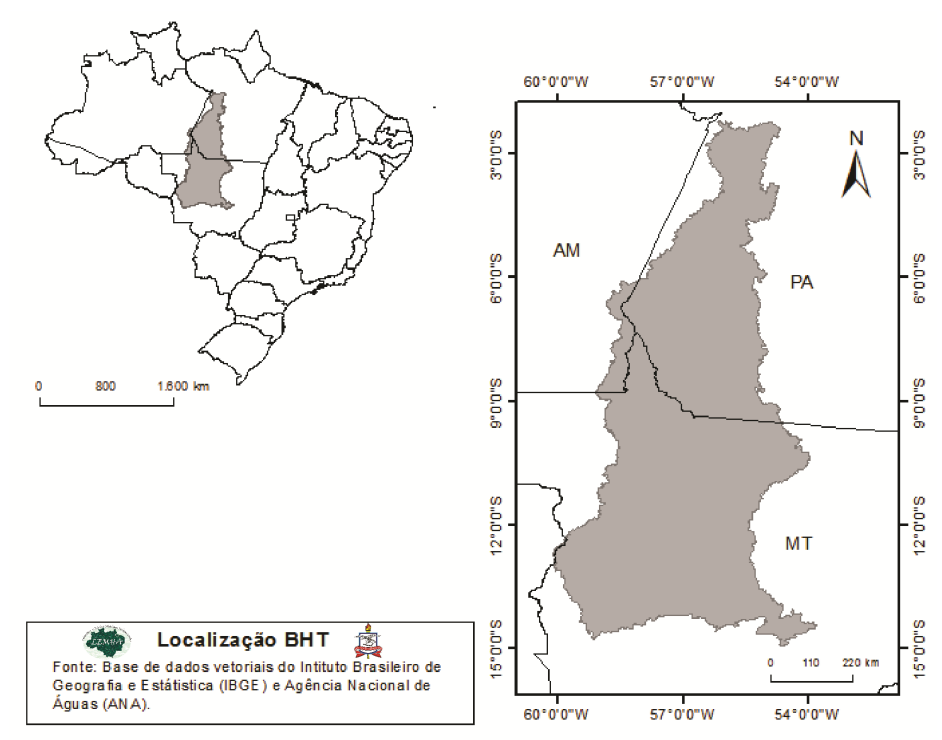

FIGURA 2. Mapa de localização da bacia do Tapajós. Fonte: Autores.

Em imagens de radar ou satélite os padrões de formas semelhantes de relevo mostram um aspecto similar quanto à rugosidade topográfica e dissecação do relevo (ROSS, 1992). Dessa forma, para a confecção da base cartográfica neste trabalho, empregou-se ainda o Modelo Digital de Elevação (MDE) definido pelo projeto Topodata, elaborado a partir dos dados SRTM disponibilizados pelo U.S. Geological Survey na rede mundial de computadores (VALERIANO \& CARVALHO JÚNIOR, 2003). Os dados SRTM apresentam resolução horizontal (i.e., resolução espacial) de 3 arco-segundos $(\sim 90 \mathrm{~m})$ e resolução vertical de $1 \mathrm{~m}$. Estes dados foram processados no software Arc Gis 10.2 (nos módulos Spacial Analyst Tools e Spacial Statistics Tools), Global Mapperv14.0, Surfer 11.0 e Corel DRAW X6.

Como mostram GOERL et al. (2012), ainda não há um consenso metodológico consolidado quanto ao estudo da hidrogeomorfologia. Dessa forma, este trabalho incorporou diferentes contribuições metodológicas, que serão expostas a seguir, de forma adaptada de acordo com os objetivos propostos nesse trabalho, propondo assim uma metodologia para caracterização hidrogeomorfológica da BHT, que será apresentada aqui em duas etapas (chamadas de etapa 1 e 2).

\section{Etapa 1}

Tem por finalidade setorizar diferentes as UHs à nível de Unidades de Terreno (UT). Essa etapa se baseia na caracterização, analise e avaliação dos atributos dos diferentes conjuntos de geoformas do terreno, como mostra DINIZ (2012), tomando como critério fundamental as características geológicas regionais da região. Para isso, o procedimento adotado foi a identificação visual dos padrões de forma semelhantes (definidos pela rugosidade topográfica), bem como, os critérios descritivos das diferentes variáveis que compõem as formas de relevo segundo ROSS (1992) e IBGE (2009.a), como pode ser visto de forma representativa na figura 3, a partir das geometrias de topo, vertentes e vales. 


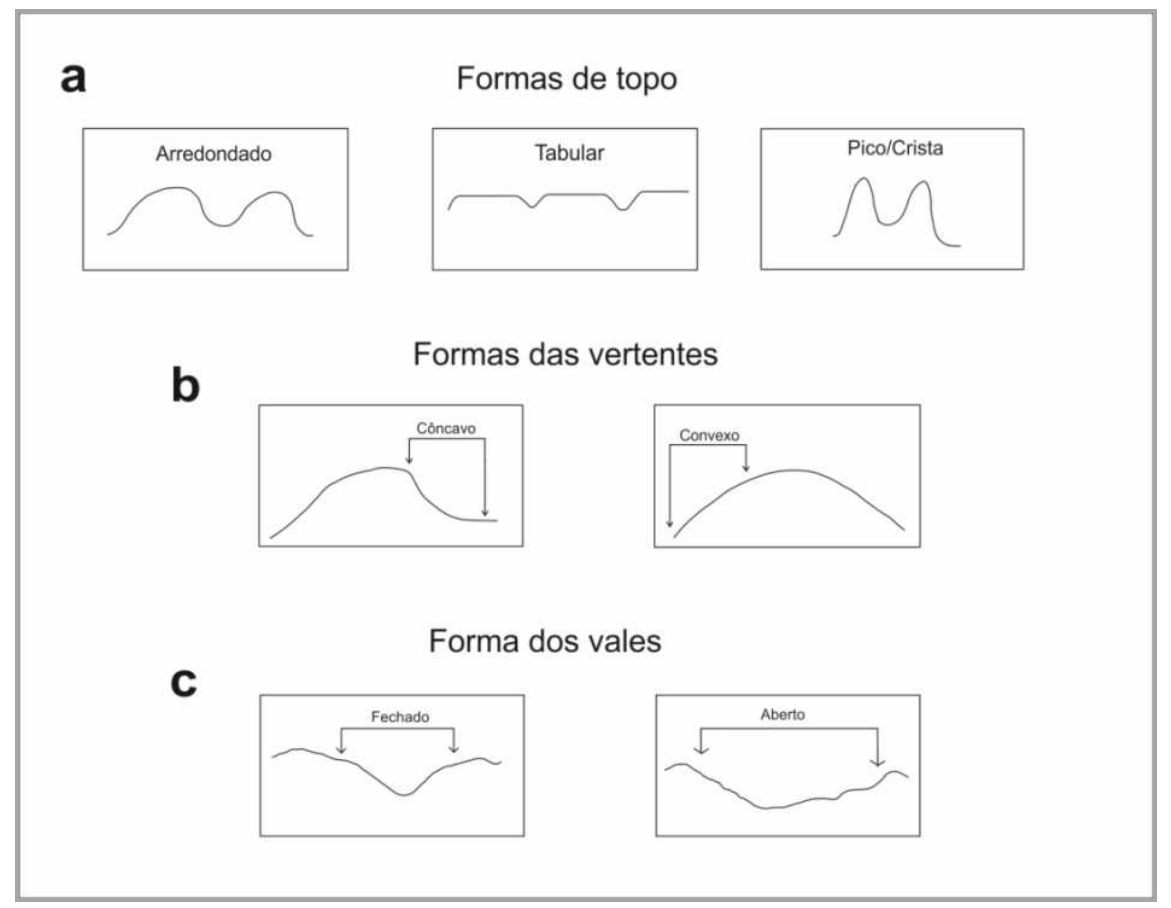

FIGURA 3. Representação esquemática das principais geometrias das formas de relevo: $\mathbf{a}$ - topo; $\mathbf{b}$ vertentes; c - vales. Fonte: Autores.

Em conjunto, foram avaliadas as classes de declividade e altimetria da região; bem como os diferentes padrões de drenagem. Ainda nesta etapa, com base na proposta de SOARES \& FIORI (1976), as propriedades da rede de drenagem foram analisadas, observando-se assim a densidade e a sinuosidade dos cursos de água presentes em cada unidade, a fim de avaliar a influência das características estruturais da região. Nesta etapa foi empregada, sempre que possível, a toponímia referencial à nomenclatura das unidades geomorfológicas segundo o IBGE (2009.b; 2006).

\section{Etapa 2}

Visou caracterizar a dinâmica hidrológica na área de estudo e integrar esta informação com as UHs, bem com os dados de vazão e pluviometria da região.

A dinâmica hidrológica foi caracterizada a partir das sub-bacias que compõem os principais afluentes da $\mathrm{BHT}$, onde foi utilizada o método de análise morfométrica da rede de drenagem - desenvolvido por STRAHLER (1952) e descritas em outros trabalhos, como o de CHRISTOFOLETTI (1980) e outros mais recentes. Desta forma, as propriedades avaliadas de forma quantitativa e sistemática neste trabalho estão expostos no quadro 1 e terão como base a compilação dos parâmetros morfométricos expostos nos trabalhos de TEODORO et al. (2007), CHEREM et al. (2011), SANTOS \& LIMA (2009), CARVALHO et al. (2012) e SANTOS et al. (2012). 
QUADRO 1. Parâmetros morfométricos hidrológicos avaliados e suas respectivas definições.

\begin{tabular}{|c|c|c|}
\hline Parâmetros & Definição & Fórmulas \\
\hline $\begin{array}{l}\text { Densidade de } \\
\text { drenagem (Dd) }\end{array}$ & $\begin{array}{l}\text { Relação entre o comprimento total dos canais de } \\
\text { drenagem em uma determinada área, que influência } \\
\text { diretamente na capacidade de infiltração e na formação de } \\
\text { canais superficiais. }\end{array}$ & $D q=L u / A\left(\mathrm{~km}^{*}\right)$ \\
\hline $\begin{array}{l}\text { Número de } \\
\text { infiltração (Ni) }\end{array}$ & $\begin{array}{l}\text { Potencial de infiltração em uma dada região em função da } \\
\text { frequência dos canais de drenagem e a densidade de } \\
\text { drenagem. }\end{array}$ & $\mathbb{N i}=F c+D d$ \\
\hline $\begin{array}{l}\text { Índice de forma } \\
\text { (K) }\end{array}$ & $\begin{array}{l}\text { Forma geral da geometria de uma bacia, na qual } \\
\text { determina a direção preferencial do escoamento da rede } \\
\text { de drenagem à medida que o valor obtido para } \mathrm{K} \text { fica } \\
\text { menor que } 1 \text {. }\end{array}$ & $K=A\left(\mathrm{~m}^{*} \mathrm{y} /\left(\mathrm{Cl}^{*}\right)\right.$ \\
\hline $\begin{array}{l}\text { Índice de } \\
\text { Sinuosidade (Is) }\end{array}$ & $\begin{array}{l}\text { Influência da litologia, carga sedimentar e estrutural de } \\
\text { uma dada área nos canais de drenagem. }\end{array}$ & $L=\frac{L}{L b}$ \\
\hline $\begin{array}{c}\text { Textura } \\
\text { Topográfica (Tt) }\end{array}$ & $\begin{array}{l}\text { Grau de dissecação do relevo e pode ser aplicado como } \\
\text { indicador do estágio de erosão de uma região. }\end{array}$ & 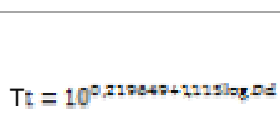 \\
\hline $\begin{array}{r}A= \\
F_{c}=\text { Fre }\end{array}$ & $\begin{array}{l}C l=\text { Comprimento do can } \\
L b=\text { Comprimento do eix }\end{array}$ & $\begin{array}{l}\text { al principal }(\mathrm{m}) \\
\text { da bacia }(\mathrm{m})\end{array}$ \\
\hline
\end{tabular}

As duas etapas, representadas de forma esquemática na figura 4, tem por finalidade reunir os diferentes conjuntos regionais de relevo frente a uma dinâmica hidrológica e climática similar que contribuem para as diferenças presentes na paisagem, auxiliando assim na compreensão da interação entre os aspectos geomorfológicos e hidrológicos da área de estudo. Vale ressaltar ainda que os nomes das diferentes UHs propostas neste trabalho foram dados em função da localização do alto, médio e baixo curso dos principais rios ao longo da BHT, como os rios Juruena, Teles Pires e Tapajós, representando assim a interação de uma determinada porção dos rios em uma unidade.

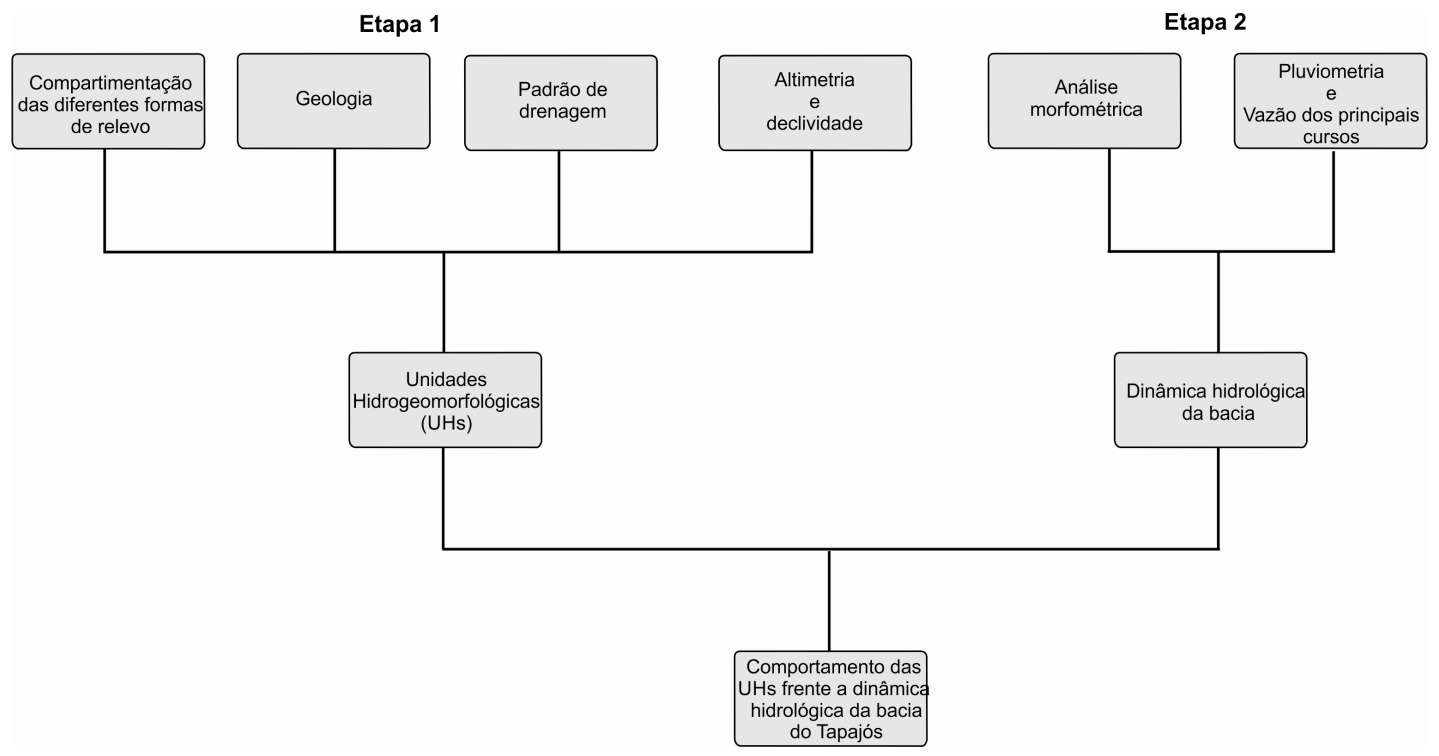

FIGURA 4. Fluxograma das etapas de setorização até a análise da paisagem na BHT. Fonte: Autores. 


\section{Geologia Regional}

A geologia nesta bacia é representada por um conjunto de rochas proterozoicas do Cráton Amazônico (CA), bem como uma porção restrita da Faixa Paraguai (borda sudeste do CA) e as rochas sedimentares fanerozoicas das bacias intracratônicas do Amazonas, Alto Tapajós e Parecis; além de coberturas cenozoicas. A disposição das unidades geológicas e geomorfológicas ao longo da bacia podem ser vistas na figura 5 .

Conforme a proposta de compartimentação geocronológica de SANTOS (2003) para o CA, as rochas na região da BHT estão inseridas no contexto das províncias proterozoicas Tapajós-Parima (2,1- 1,87 Ga.), Amazônia Central (1,88-1,70 Ga.) e Rondônia-Juruena (1,76-1,47 Ga.). O quadro litológico destas províncias na área de estudo é bastante variado, sendo constituídas por associações, por vezes deformadas, com estruturação principal em NW-SE, sendo representadas por: granitóides de composições variadas de forma expressiva, rochas vulcânicas félsicas a máficas, bem como associações metavulcanossedimentar e de alto grau metamórfico. Apresentando um aspecto diferencial das demais províncias, a Província Rondônia-Juruena apresenta inliers de suítes intrusivas do embasamento, metamorfizados de baixo até alto grau metamórfico, que estão envolvidos por rochas magmáticas mais jovens (FILHO et al. 2004; VASQUEZ \& ROSA-COSTA 2008).

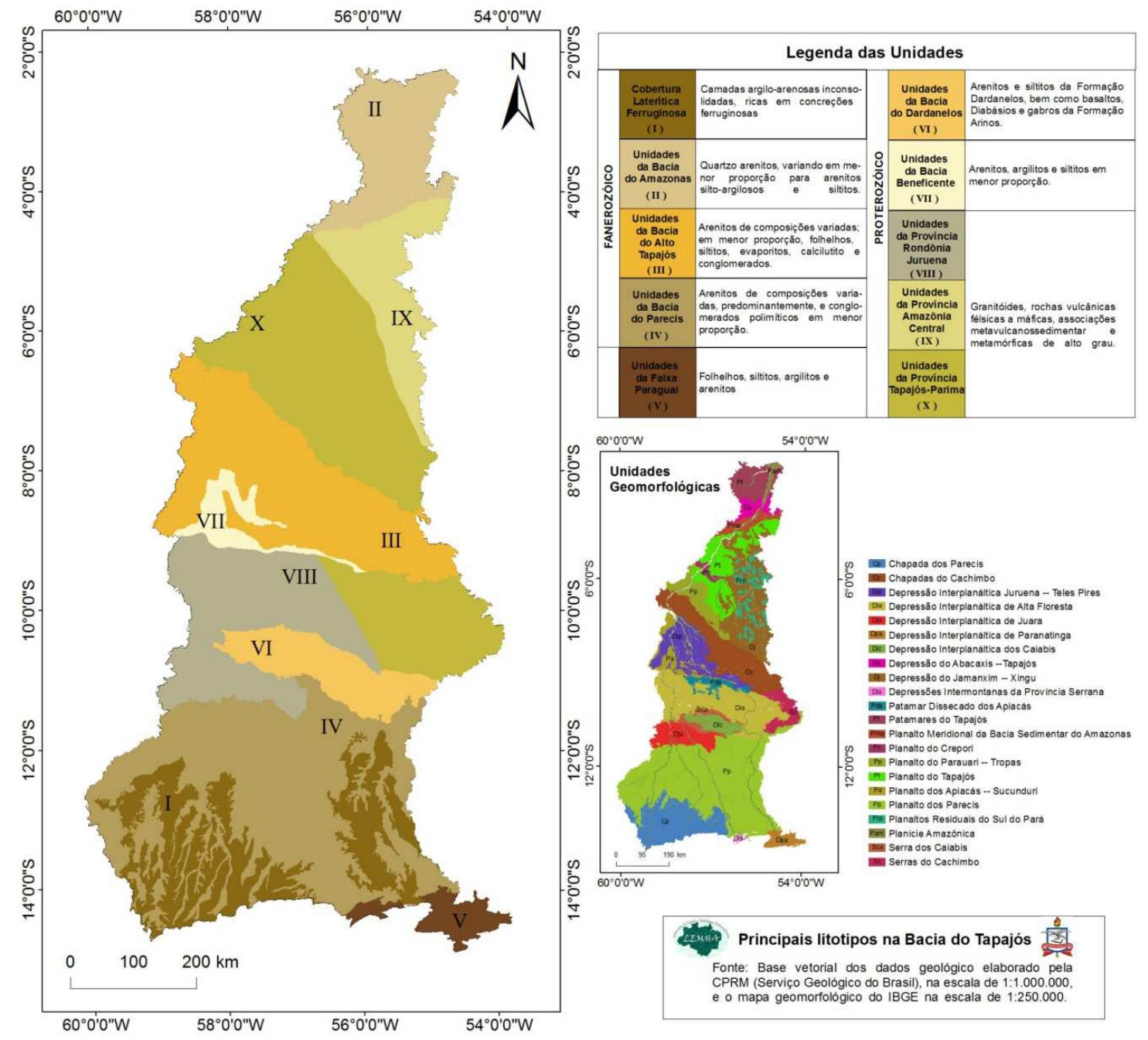

FIGURA 5. Distribuição dos principais litotipos e unidades geomorfológicas ao longo da Bacia do Tapajós. Fonte: Autores. 
Ainda no complexo contexto geológico do $\mathrm{CA}$, sobrepostas às sequências cristalinas da Província Rondônia-Juruena, na região nordeste do estado do Mato Grosso, encontra-se aflorante unidades das Bacias proterozoicas Beneficente (BB) e Dardanelos (BD), como mostram FILHO et al. (2004), representadas pela Unidade Beneficente (BB) e o Grupo Caiabís (formações Arinos e Dardanelos), respectivamente. Os litotipos da BB na área de estudo são constituídos por arenitos, bem como argilitos e siltitos em menor proporção, que, por vezes, formam estruturas dômicas presentes nessa região. As rochas do Grupo Caiabis são representadas por arenitos e siltitos da Formação Dardanelos, além de basaltos, diabásios e gabros da Formação Arinos.

No extremo sudeste da BHT, os sedimentos proterozoicos são representados por folhelhos, siltitos, argilitos e arenitos da Faixa Paraguai. Como mostram ALVARENGA \& TROMPETTE (1993), as rochas da Faixa Paraguai são caracterizadas por sequências de rochas metavulcanicas, metassedimentares e sedimentares, orientadas em NE-SW, que foram deformadas no evento Brasiliano (550-500 Ma). As rochas da Faixa Paraguai na região de estudo são representadas pelas formações Diamantino e Raizama (Grupo Alto Paraguai), inseridas na chamada "zona externa dobrada", que apresentam litotipos com pouco ou nenhum metamorfismo associado.

As coberturas sedimentares fanerozoicas ocorrem em grande parte da área de estudo, sendo representadas pelas rochas das bacias do Amazonas, Alto Tapajós e Parecis, que tiveram sua evolução iniciada a partir de eventos extensionais Neoproterozoicos a Eopaleozoicos no CA, conforme exposto por FILHO et al. (2004), VASQUEZ \& ROSA-COSTA (2008) e VASQUEZ et al. (2008).

A região sul da BHT é constituída por sequências da Bacia do Parecis, composta, predominantemente, por arenitos variados das formações Utiariti e Salto da Nuvens, ocorrendo conglomerados polimíticos em menor proporção nesta última. Estas sequências formam a Chapada do Parecis.

$\mathrm{Na}$ região central, as sequências sedimentares da Bacia Alto Tapajós são formadas por quartzo arenitos finos a médios, de forma geral, das formações Capoeiras, Igarapé Ipixuna e São Manuel, variando em menor proporção para arenitos silto-argilosos e siltitos, que compõem a Serra do Cachimbó.

Já a porção norte da BHT, representada pelas rochas da Bacia do Amazonas, é constituída de forma expressiva por arenitos de composições variadas do Membro Lontra (ML), Grupo Curuá (GC) e as formações Monte Alegre (FMA), Itaituba (FI), Nova Olinda (FNO) e Alter do Chão (FAC). Em menor proporção, há a presença de folhelhos e siltitos em GC e FI, evaporitos em FNO, calcilutito em FI, bem como conglomerados em ML.

As coberturas cenozoicas representam os últimos registros litoestratigráficos na $\mathrm{BHT}$, sendo representadas por depósitos lateríticos, de idade terciária, e depósito inconsolidados quaternário ao longo do leito dos rios, sendo este ultima representado de forma expressiva pela Planície Amazônica ao longo do leito dos principais rios da BHT.

\section{Clima e hidrografia regional}

Drenando uma área de aproximadamente $155 \mathrm{mil} \mathrm{km}^{2}$, o canal principal do rio Tapajós inicia na porção norte da BHT, em altitudes próximas ao nível do mar, e segue seu curso a sudoeste, até formar seu exutório nos rios Jamaxim e Crepori, em regiões mais elevadas, com altitude de aproximadamente $68 \mathrm{~m}$, tal que estes 
possuem suas vazões somadas às dos rios Juruena e Teles Pires (cabeceira da bacia do Tapajós) e do rio Aripuans.

A partir da regionalização das cotas fluviométricas e vazão de diferentes séries históricas das sub-bacias do Juruena, Teles Pires e Médio Baixo Tapajós, SANTOS et al. (2015) apresentam que as médias anuais nos postos fluviométricos localizados próximo a foz dos rios Juruena, Teles Pires e Tapajós, como pode ser visto na figura 6, apresentam os valores: $4.655 \mathrm{~m}^{3} / \mathrm{s} ; 3.667 \mathrm{~m}^{3} / \mathrm{s} ; 12.259 \mathrm{~m}^{3} / \mathrm{s}$, respectivamente. Dessa forma, nota-se que há um aumento nos valores de vazão no sentido da porção mais alta até às regiões mais baixas da bacia, em direção a foz do rio Tapajós.

No contexto da classificação climática de Köppen-Geiger, SANTOS et al. (2014) enquadram a BHT em duas tipologias climáticas: $A m$ a norte, que caracteriza o clima tropical de monção; e Aw na porção sul, com clima tropical de verão seco (tendo uma estação seca mais intensa em relação ao clima $A m$ ). Estes ressaltam que os totais pluviométricos anuais, obtidos a partir da série histórica 1985-2012, variam de $1.560 \mathrm{~mm}$ na região de clima $A w$ e crescem a norte para valores que chegam a $2.433 \mathrm{~mm}$. Assim, a partir do zoneamento da distribuição de precipitação pluviométrica na BHT, os mesmos autores afirmam que as diferentes tipologias climáticas refletem as diferenças quanto à distribuição pluviométrica, como pode ser visto na figura 6, caracterizando a cabeceira da BHT como a zona de maior sensibilidade as variações de precipitação.
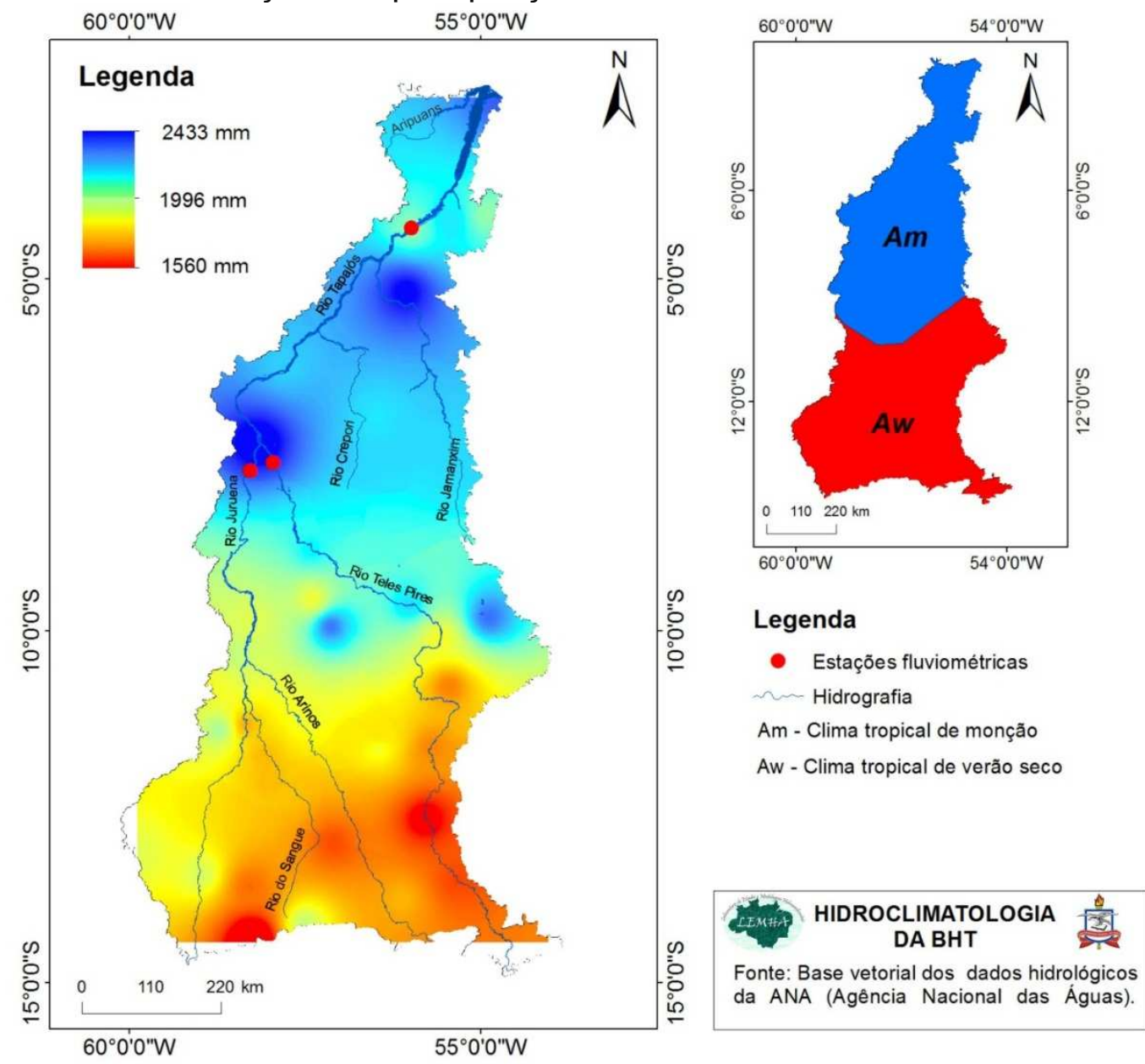

FIGURA 6. Média anual da precipitação pluviométrica (série histórica 1985-2012), tipologias climáticas e hidrografia regional no contexto da Bacia do Tapajós. Fonte: Autores. 


\section{RESULTADOS E DISCUSSÃO}

Com uma expressiva variabilidade nos diferentes atributos com compõem o relevo, bem como na geologia da região, a BHT foi compartimentada em nove UHs, como pode ser visto na figura 7. Estas serão descritas a seguir seguindo, respectivamente, das unidades mais altas até às mais baixas que ocorrem ao longo de toda bacia.

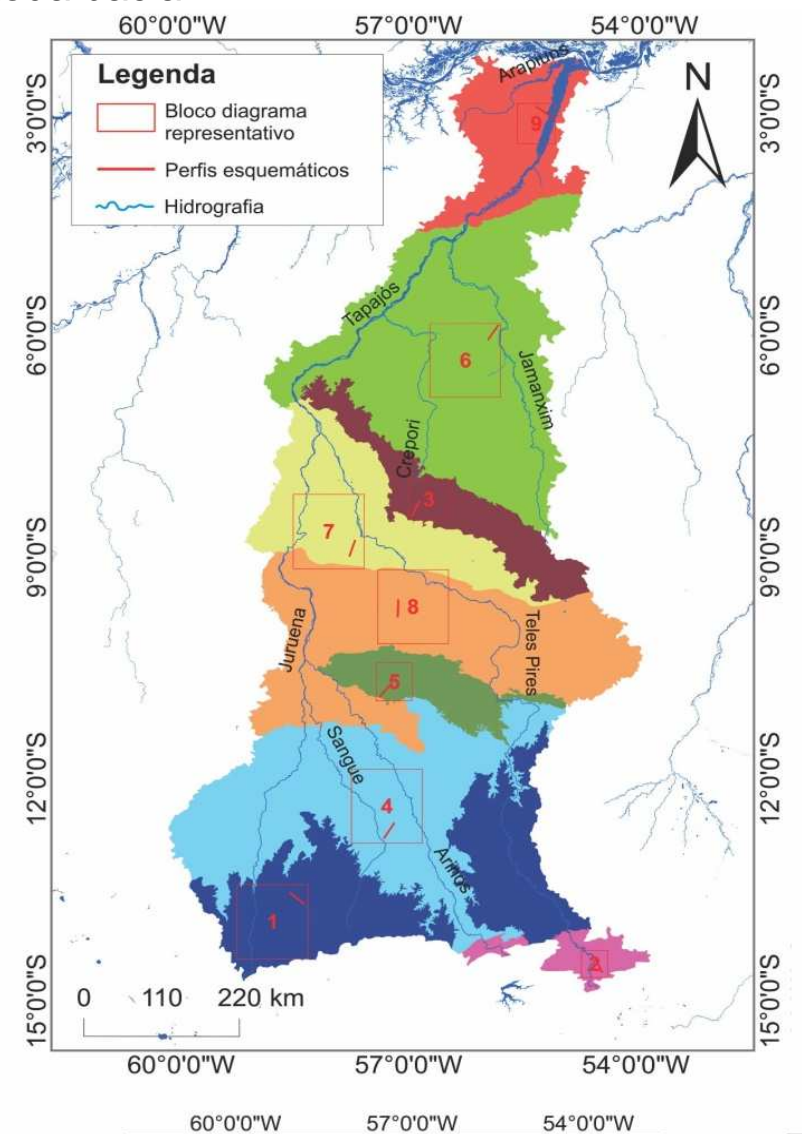

\begin{tabular}{|l|c|}
\hline UHs & Área $\left(\mathbf{k m}^{\mathbf{2}}\right)$ \\
\hline Alto Juruena & 69.630 \\
\hline Alto Teles Pires & 9.133 \\
\hline Alto Tapajós & 27.008 \\
\hline Médio Juruena & 92.702 \\
\hline Médio Teles Pires & 18.810 \\
\hline Médio Tapajós & 109.682 \\
\hline Médio Baixo Juruena & 84.847 \\
\hline Baixo Juruena & 47.180 \\
\hline Baixo Tapajós & 33.138 \\
\hline
\end{tabular}
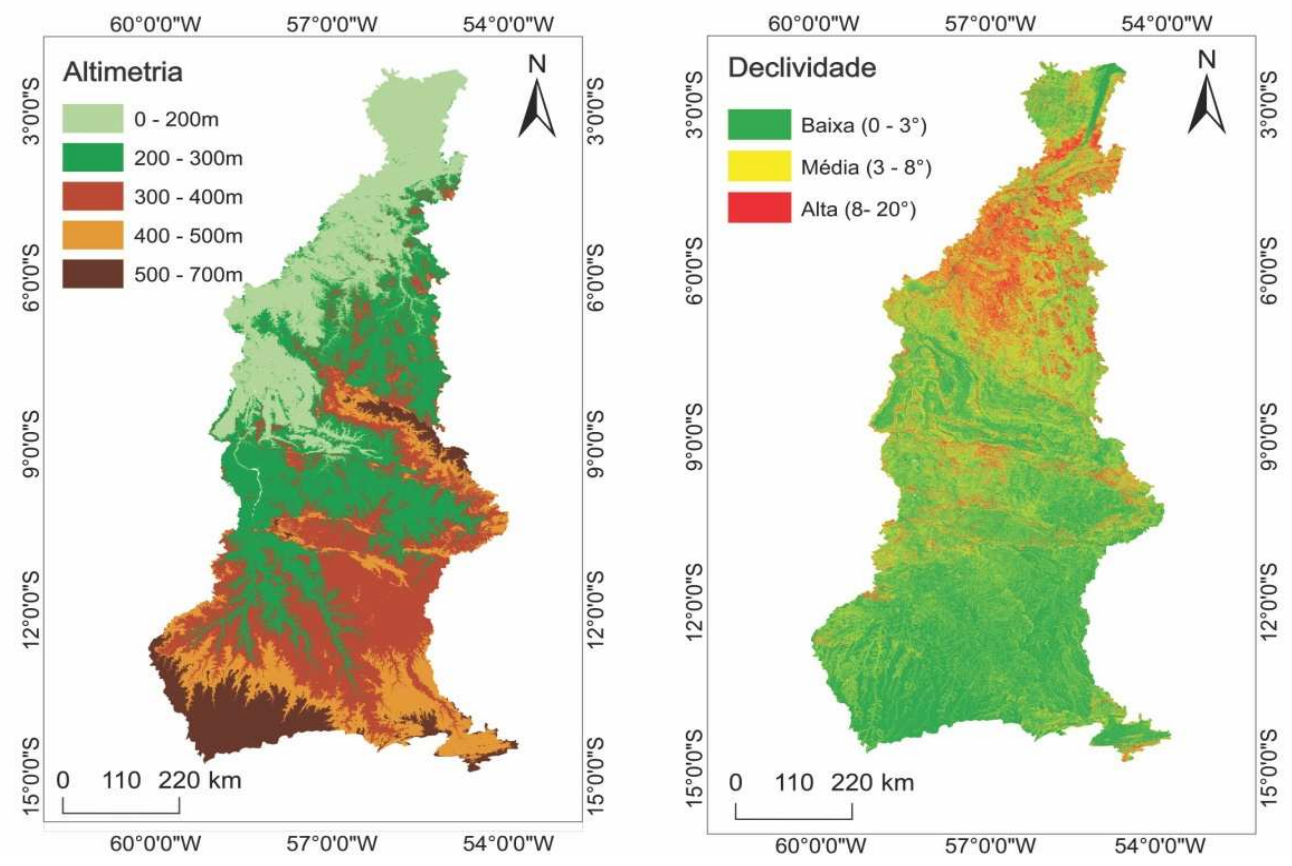

FIGURA 7. Unidades Hidrogeomorfológicas, altimetria e declividade da Bacia do Tapajós. Fonte: Autores. 


\section{UH Alto Juruena}

Constituindo a região mais alta da bacia, com cotas que variam de 400 a $700 \mathrm{~m}$, no entorno da região centro-oeste do estado do Mato Grosso, ao longo da Chapada do Parecis (figura 8.1.A). Esta unidade apresenta baixos valores de declividade e caracteriza-se por serras que possuem formas de topo arredondado a tabular, com predomínio de vertentes côncavas e vales fechados em forma de V. Este conjunto de formas é embasado por arenitos e conglomerados polimíticos pertencentes a Bacia do Parecis e é sustentado por uma espessa crosta laterítica ferruginosa endurecida que ajuda a retardar a ação dos processos erosivos.

O padrão de drenagem expressivo nesta unidade é o paralelo, seguindo o curso dos rios Juruena, do Sangue e Teles Pires, próximo as suas respectivas nascentes nas regiões serranas, ao longo dos vales encaixados nesta unidade, denotando assim um controle estrutural na área que conferem aos cursos uma direção preferencial dos cursos em NE-SW que varia localmente para NEN-SWS na porção leste da mesma.

\section{UH Alto Teles Pires}

Representando a menor unidade de toda bacia do Tapajós, na porção sudeste do Mato Grosso, esta área apresenta terrenos aplainados e morros alinhados em cotas elevadas, que variam entre 700 e $450 \mathrm{~m}$, tal que estes valores altimétricos são gradualmente decrescentes de sul para norte, seguindo o curso do vale do rio Teles Pires ao longo da Depressão Interplanaltica Paranatinga. Os valores de declividades são predominantemente médios, variando localmente para valores baixos nas regiões aplainadas e altos nas porções mais elevadas.

As formas de relevo apresentam topo em pico e vertentes predominantemente convexas nas porções alinhadas e topos arredondados com vertentes côncavas nas porções aplainadas, bem como vales abertos em formas de $U$ ao longo de toda unidade. Estas formas são constituídas por rochas sedimentares da zona externa dobradas da Faixa do Paraguai, tal que os eventos deformacionais ocorridos na região foram responsáveis pela estruturação das formas de relevo, representado pelas cristas que apresentam orientação preferencial em ENE-WSW, como pode ser visto na figura 8.2.A. Além disso, o trend regional controla também os padrões e as direções dos cursos de drenagem na região, sendo representada pelo padrão treliça com direção preferencial acompanhando a estruturação do relevo.

\section{UH Alto Tapajós}

Localizada na porção sudoeste do estado do Pará, esta unidade representa um sobressalto topográfico dissecado com relação às superfícies aplainadas das unidades adjacentes, com cotas que variam de 350 a $650 \mathrm{~m}$, cujas altitudes decrescem ligeiramente de norte para sul. Esta unidade esta inserida no contexto geomorfológico da Chapada do Cachimbó (DANTAS \& TEIXEIRA, 2013), e apresenta uma variabilidade nas classes de declividade ao longo de toda sua extensão, onde predominam as altas declividades. O conjunto de formas de relevo é representado por feições com topo arredondado a tabular e vertentes assimétricas, caracterizando uma feição de cuesta, na qual predominam a forma côncava, bem como vales aberto (figura 8.3.D).

Esta região é constituída por arenitos e siltitos da Bacia do Alto Tapajós e apresentam uma orientação preferencial em NW-SE, que coincide com a estruturação regional desta bacia sedimentar, como mostra REIS et al. (2006). Nesta região ocorre também a nascente do rio Crepori, afluente do rio Tapajós, cujo 
padrão de drenagem dos cursos é dendritico e apresenta uma orientação preferencial pouco expressiva em NE-SW.

\section{UH Médio Juruena}

Estando na porção noroeste do Mato Grosso, esta unidade é constituída por arenitos e conglomerados polimíticos da Bacia do Parecis, no contexto do Planalto do Parecis, e apresenta cotas altimétricas que variam de 200-400m, bem como valores de declividade que variam de média a baixa. É composta por um conjunto de serras e morros separados por vales profundos esculpidos pela ação da dinâmica fluvial na região (figura 8.4.A). As formas de relevo apresentam topo arredondado, bem como o predomínio de vertentes côncavas e vales fechados em forma de $V$, com ocorrência local de vales abertos.

Banhada pelo médio curso do rio Juruena, bem como seus afluentes (rio do Sangue e Arinos), nesta unidade os padrões de drenagem presente são os dendríticos e treliça, tal que estes últimos evidenciam eventual controle estrutural nos cursos de maior ordem e são representadas pelas orientações preferenciais em NWN-SES e, de forma mais local, NE-SW.

\section{UH Médio Teles Pires}

Com cotas que variam de 200 a 400m, na porção noroeste do Mato Grosso, esta unidade apresenta valores baixos a médios de declividade e caracteriza-se por apresentar dois conjuntos principais quanto as formas de relevo, sendo representados por uma região aplainada na região central, chamada de Depressão Interplanaltica dos Caiabis, e por uma porção mais elevada na Borda desta unidade, a Serra dos Caiabis.

Inserida no contexto da Bacia mesoproterozoica do Dardanelos, FILHO et al. (2004) ressalta que a mesma possui uma estruturação alongada em WNW-ESSE e possui uma borda marcada por zonas de cisalhamento transcorrentes. O mesmo autor ressalta ainda que a região da Serra dos Caiabis é constituída litologicamente por rochas sedimentares da Formação Dardanelos intercaladas com sills de rochas máficas da Formação Arinos. Nota-se o relevo mais elevado com orientação preferencial na borda desta unidade, ligado a direção da zona de cisalhamento, e caracterizado por formas de relevo com topos arredondados e vertentes predominantemente côncavas.

As regiões aplainadas no centro desta unidade são representadas por morros suaves com topo arredondado, vertentes predominantemente côncavas e vales abertos em forma de $U$ (figura 9.5.A), bem como pela baixa variabilidade nas classes de declividade na região. Os padrões de drenagem nessa região são treliça, denotando controle estrutural dos cursos com direção em NE-SW, e dendrítico de forma local.

\section{UH Médio Tapajós}

Localizada no extremo sudoeste do estado do Pará, esta unidade apresenta uma região aplainada que apresenta feições residuais de relevo. Estas feições geomorfológicas estão esculpidas em terrenos Pré-Cambrianos constituídos por rochas cristalinas e metavulcanossedimentares das províncias Tapajós-Parima e Amazônia Central. 

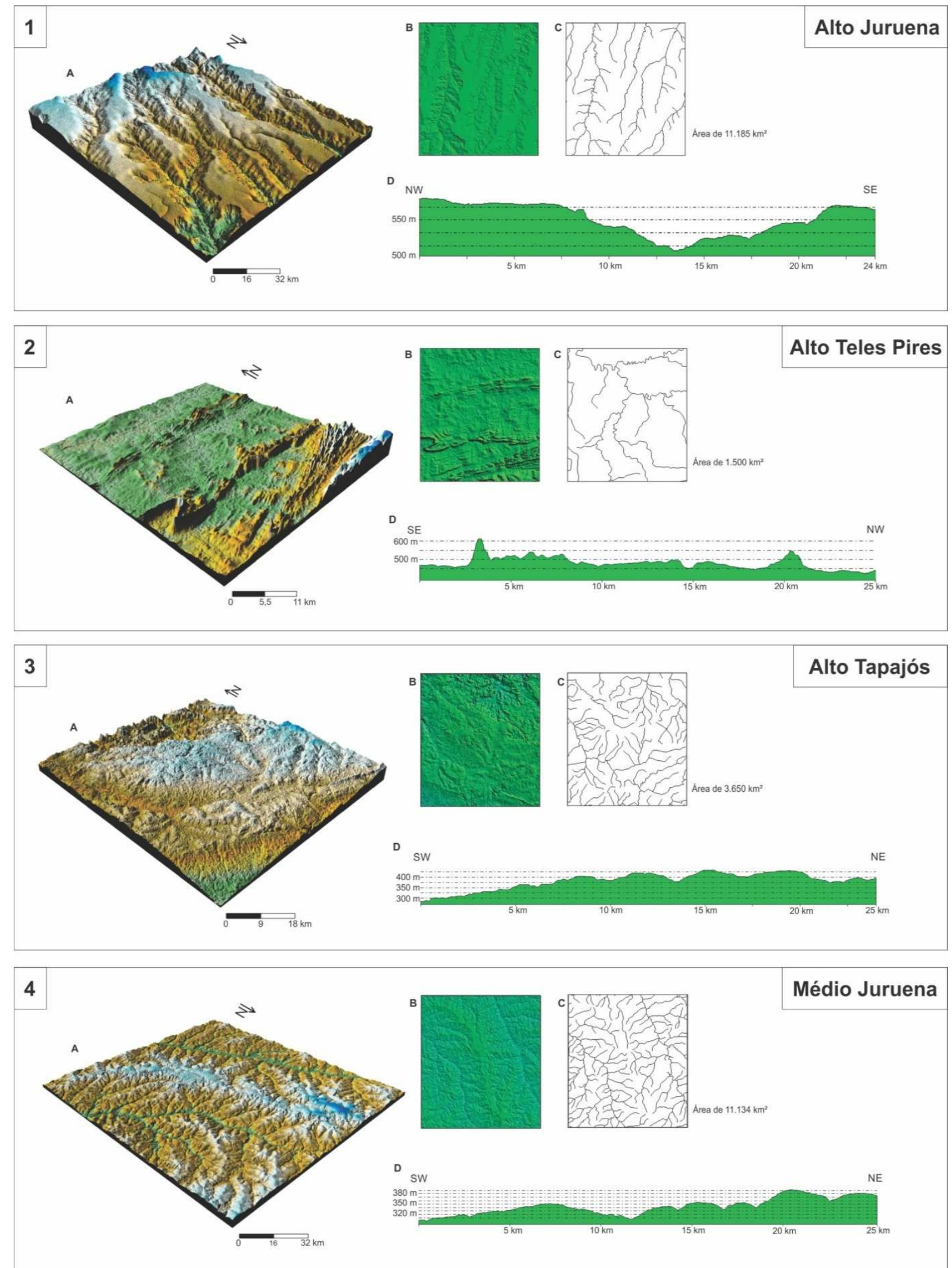

FIGURA 8. Imagem esquemática dos diferentes aspectos do relevo presente nas UHs: 1 - Alto Juruena; 2 - Alto Teles Pires; 3 - Alto Tapajós; 4 - Médio Juruena. A - bloco diagrama do arranjo geomorfológico; B - aspecto textural; C - padrão de drenagem; D - perfil típico das geofomas. Fonte: Autores. 
Com cotas que variam, predominantemente, de 0 a $300 \mathrm{~m}$, esta unidade apresenta predomínio de altos valores de declividade, onde o terreno fica mais baixo e aplainado à medida que se aproxima do médio curso do leito dos rios Tapajós e Teles Pires. Há ocorrências, de forma espaçada, de morros residuais que alcançam até $400 \mathrm{~m}$ de altitude, tal que estes estão inseridos na região dos Planaltos residuais do Sul da Amazônia (DANTAS \& TEIXEIRA, 2013; VALENTIM \& OLIVITO, 2011).

As porções aplainadas, bem como as formas residuais do relevo nesta unidade são representadas por morros suaves com topo em forma de pico a arredondada, vertentes predominantemente convexas e vales abertos em forma de $U$, como podem ser visto na figura 9.6.D. Os padrões de drenagem presente são o dendrítico e a treliça, onde este último indica suave controle estrutural na região, com direção preferencial dos cursos de maior ordem em NW-SE - acompanhando assim o tred regional dos eventos metamórficos que aturam nas rochas da região, como mostra FILHO et al. (2004).

\section{UH Médio Baixo Juruena}

Situada na porção extremo norte do estado do Mato Grosso, próximo à fronteira com os estados do Pará e Amazonas, esta unidade constitui uma região aplainada inserida na Depressão Interplanáltica do Juruena-Teles Pires, cujas formas de relevo foram esculpidas em terrenos cristalinos, bem como metavulcanossedimentar das províncias Amazônia-Central e Rondônia-Juruena. Ocorrem também feições residuais de relevo, como o Patamar Dissecado do Apiacás-Sucunduri e inselberg esparçados, que são sustentados por rochas mais resistentes aos processos de intemperismo e erosão em relação às rochas adjacentes.

As regiões mais baixas ocorrem em cotas que variam de 200 a 300m, onde as áreas mais rebaixadas estão preferencialmente próximas aos leitos dos rios Juruena e Teles Pires, enquanto as cristas das feições espaçadas mais elevadas nesta unidade podem alcançar altitudes de até $450 \mathrm{~m}$. Os valores predominantes de declividade são os medianos, com ocorrência de declives baixos e altos em menor proporção.

As formas de relevo apresentam forma de topo em pico a arredondado, vertentes predominantemente côncavas e vales abertos com forma de $U$ (figura 9.7.D). Os padrões de drenagem nesta unidade são o dendrítico e a treliça, onde este último apresenta orientações preferenciais em WNW-ESSE e indicam assim um controle estrutural na qual os leitos dos rios se instalaram preferencialmente.

\section{UH Baixo Juruena}

Localizada na divisa entre os estados do Pará, Mato Grosso e Amazonas, a sul da Chapada do Cachimbó, esta unidade apresenta um conjunto de serras e morros inseridos na Depressão Interplanáltica Juruena-Teles Pires. Com cotas de 0-300m e porções mais elevadas que ocorrem de forma descontinua, com altitudes de até $400 \mathrm{~m}$, as formas de relevo descritas são constituídas por rochas sedimentares das bacias do Alto Tapajós e Beneficente, sendo representadas, de forma geral, por arenitos, argilitos e siltitos.

Assentadas de forma discordante às rochas cristalinas do CA na região, as litologias que compõem esta unidade apresentam, por vezes, ressaltos topográficos em formas de domos, bem como feições alinhadas no relevo nessa região (figura 9.8.A), estando assim associado ao controle estrutural das rochas deformadas que estão sobrejacentes a essa região. 

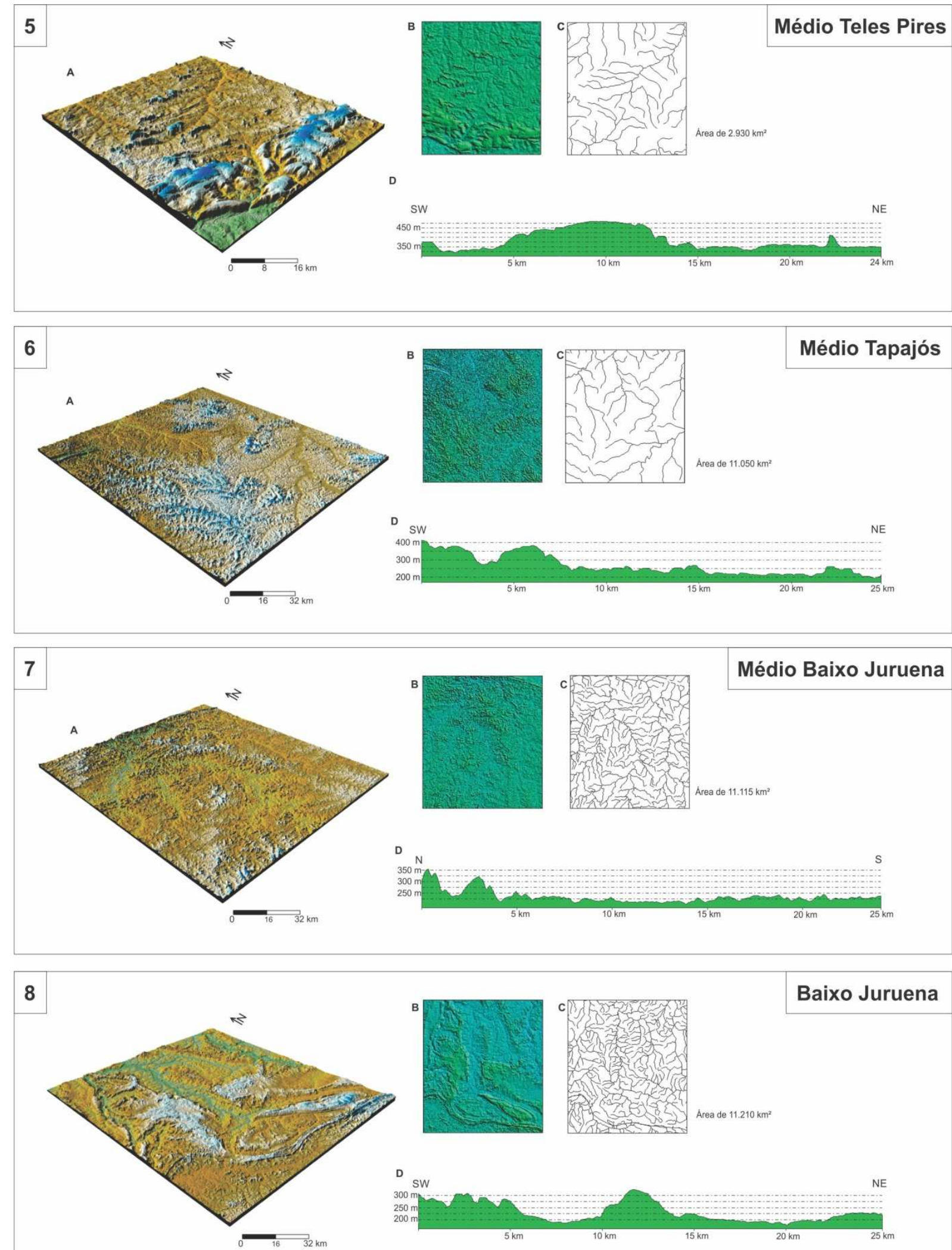

Baixo Juruena

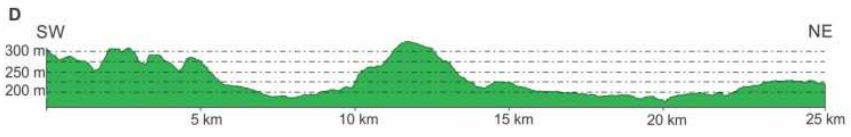

FIGURA 9. Imagem esquemática dos diferentes aspectos do relevo presente nas UHs: 5 - Médio Teles Pires; 6 - Médio Tapajós; 7 - Médio Baixo Juruena; 8 - Baixo Juruena. A - bloco diagrama do arranjo geomorfológico; B - aspecto textural; C - padrão de drenagem; D - perfil típico das geofomas. Fonte: Autores. 
As formas de relevo apresentam topos arredondados a tabular, com predomínio de vertentes côncavas e vales abertos em forma de U. Estas geoformas apresentam vertentes com declives, predominantemente, baixos a médios. Os padrões de drenagem presente são o dendrítico e treliça, tal que estes últimos apresentam direção preferencial em NW-SE dos seus cursos. De forma local, ocorrem os padrões anelar, tal que este está associado as formas de domos presentes, de forma descontinua, na região.

\section{UH Baixo Tapajós}

Situada na região centro-oeste do estado do Pará, esta é a unidade mais baixa, com cotas modestas, que variam de 0 a $200 \mathrm{~m}$, e declives variados, que vão desde fortes em feições geomorfológicas com vertentes íngremes até valores mais suaves ao longo do baixo curso do rio Tapajós nessa região, que está inserida na chamada Planície Amazônica.

Esta região é caracterizada por serras e morros que ocorrem ao longo do Patamar do Tapajós e a Depressão do Abacaxis-Tapajós, as feições geomorfológicas são embasadas pelas rochas sedimentares da Bacia do Amazonas e apresentam topo arredondado a tabular, com predomínio de vertentes côncavas, bem como vales abertos em forma de $U$, como pode ser visto no perfil típico dessa unidade na figura 10.9.D.

Nota-se que não há uma direção preferencial expressiva nos cursos de água de menor ordem nesta região, tal que o padrão de drenagem característico é o dendrítico. No entanto, vale ressaltar que a direção preferencial em NE-SW do curso de maior ordem no entorno da foz do rio Tapajós se encontra instalada em uma região de gráben (área constituída por um baixo estrutural), evidenciado pelo forte controle de falhas normais existentes ao longo dos vales desse rio (COSTA et al. 1996; COSTA et al., 2001).

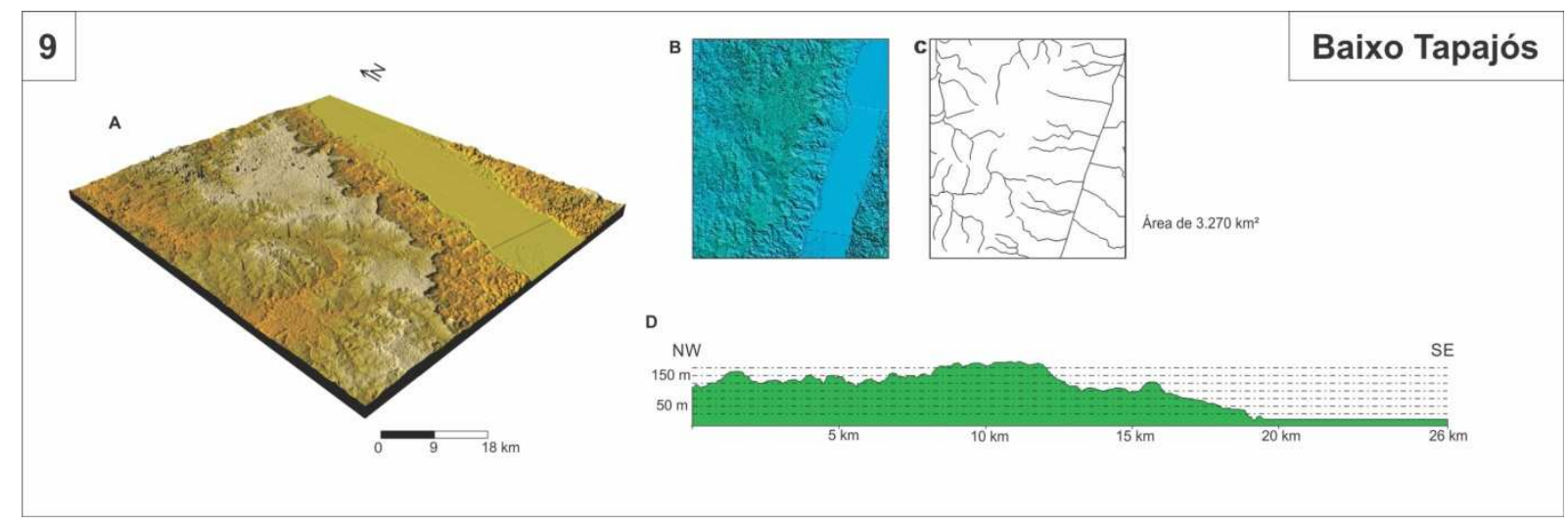

FIGURA 10. Imagem esquemática dos diferentes aspectos do relevo presente na unidade hidrogeomorfológica do Baixo Tapajós. 9 - Baixo Tapajós; A bloco diagrama do arranjo geomorfológico; B - aspecto textural; C padrão de drenagem; D - perfil típico das geofomas. Fonte: Autores.

\section{Analise morfométrica}

A dinâmica hidrológica das sub-bacias de $5^{\underline{a}}$ a $7^{\text {a }}$ ordem que compõem a BHT, com base proposta de hierarquização de STRAHLER (1952), foram analisadas a partir dos resultados dos parâmetros morfométricos da tabela 1 . 
TABELA 1. Resultado numérico dos parâmetros morfométricos calculados para as oito sub-bacias da BHT.

\begin{tabular}{c|c|c|c|c|c|c|c|c}
\hline \multirow{2}{*}{$\begin{array}{c}\text { Parâmetros } \\
\text { Morfométricos }\end{array}$} & $\begin{array}{c}\text { Alto } \\
\text { Juruena }\end{array}$ & $\begin{array}{c}\text { Rio do } \\
\text { Sangue }\end{array}$ & $\begin{array}{c}\text { Rio } \\
\text { Arinos }\end{array}$ & $\begin{array}{c}\text { Médio- } \\
\text { Baixo } \\
\text { Juruena }\end{array}$ & $\begin{array}{c}\text { Teles } \\
\text { Pires }\end{array}$ & $\begin{array}{c}\text { Médio } \\
\text { Tapajós }\end{array}$ & $\begin{array}{c}\text { Rio } \\
\text { Jamaxim }\end{array}$ & $\begin{array}{c}\text { Baixo } \\
\text { Tapajós }\end{array}$ \\
\hline $\begin{array}{c}\text { Densidade de } \\
\text { drenagem (Dd) }\end{array}$ & 165,72 & 185,04 & 194,98 & 280,98 & 245,13 & 160,74 & 161,79 & 181,46 \\
\hline $\begin{array}{c}\text { Número de } \\
\text { infiltração (Ni) }\end{array}$ & 2,70 & 3,88 & 3,83 & 28,63 & 6,84 & 2,07 & 2,22 & 3,19 \\
\hline $\begin{array}{c}\text { Indice de forma } \\
\text { (K) }\end{array}$ & 0,41 & 0,11 & 0,09 & 0,17 & 0,06 & 0,44 & 0,13 & 0,47 \\
\hline $\begin{array}{c}\text { Indice de } \\
\text { Sinuosidade } \\
\text { (Is) }\end{array}$ & 2,07 & 2,91 & 3,44 & 2,46 & 4,60 & 2,11 & 3,09 & 1,89 \\
\hline $\begin{array}{c}\text { Textura } \\
\text { Topográfica (Tt) }\end{array}$ & 494,62 & 559,33 & 592,91 & 891,11 & 765,29 & 478,05 & 481,54 & 547,27 \\
\hline
\end{tabular}

A partir da análise comparativa, nota-se que em termos de Densidade de Drenagem (Dd) e Número de Infiltração (Ni), destacam-se com os valores mais elevados de toda BHT as sub-bacias do Teles Pires e Médio-Baixo Juruena, sendo o valor de $\mathrm{Ni}$ mais expressivo neste último. Com valores opostos, as sub-bacias do Alto Juruena, Médio Tapajós e do Rio Jamaxim destacam-se por apresentar valores mais baixos desses parâmetros.

Quanto a geometria da bacia, o Índice de Forma (K), ou de circularidade, as sub-bacias do Alto Juruena, Médio Tapajós e Baixo Tapajós apresentam a geometria mais circular, representada pelos valores mais próximos a 1, como mostram COUTINHO et al. (2011) e SILVA et al. (2014). Dessa forma, nota-se que apesar das três obterem valores similares, apenas as sub-bacias mais próximas à foz do rio Tapajós (Médio Tapajós e Baixo Tapajós) são mais favoráveis ao acumulo de água, pois a água da montante escoa em direção as áreas mais rebaixadas. No outro extremo, com valores que indicam uma geometria mais triangular, as subbacias do Teles Pires e dos rios do Sangue e Arinos, bem como do Médio-Baixo Juruena, são áreas mais favoráveis aos processos de escoamento superficial.

A remoção e a deposição de sedimentos nos cursos dos rios são menos favoráveis nas sub-bacias no Alto Juruena e Baixo Tapajós (com relação às subbacias do Teles Pires, bem como dos rios Arinos e Jamaxim), evidenciado pelos valores mais baixos do Índice de Sinuosidade (Is), ou sinuosidade dos canais (DAS et al. 2012; PARETA \& PARETA, 2012). As áreas que apresentam menor índice de sinuosidade coincidem também com as de menor valor de Tt ao longo de toda BHT, junto com as sub-bacias do Médio Tapajós e do rio Jamaxim, tal que estas regiões se distinguem dos valores mais elevados de Tt presente nas sub-bacias do Teles Pires e do Médio Baixo Juruena, sendo mais expressiva nesse último.

A partir da interpretação dos dados morfométricos, nota-se que a dinâmica hidrológica na bacia do Tapajós apresenta dois principais comportamentos, representado por regiões de menor dinâmica hidrológica (MEDH) e maior dinâmica hidrológica (MADH). (figuras 11 e 12) 


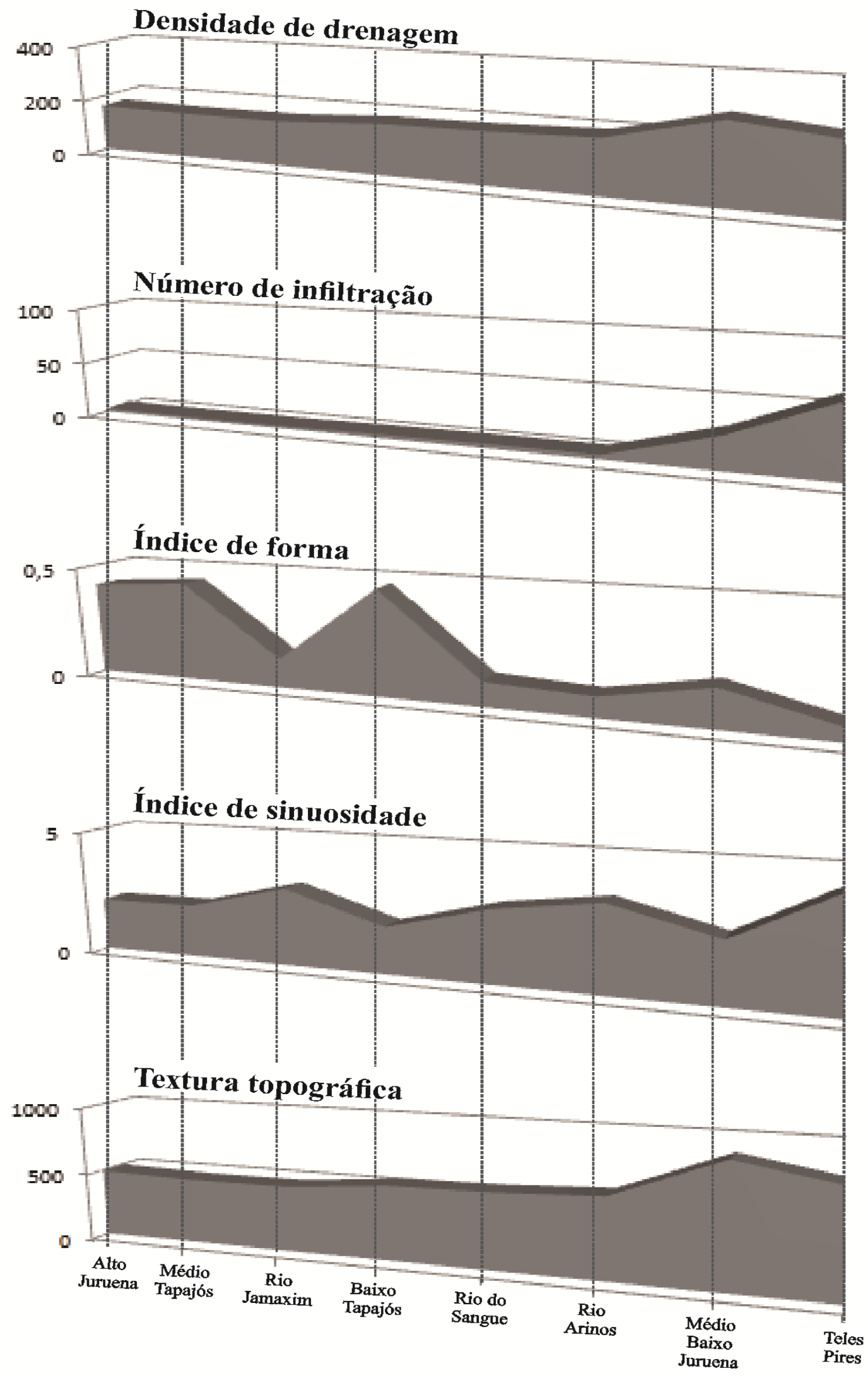

FIGURA 11. Comparação gráfica entre os dados das regiões de maior e menor dinâmica hidrológica na BHT. Fonte: Autores. 


\begin{tabular}{|c|c|c|c|c|}
\hline & Sub-bacias & Hierarquia & Área $\left(\mathrm{km}^{2}\right)$ & $\begin{array}{c}\text { Número total de } \\
\text { canais }\end{array}$ \\
\hline \multirow{4}{*}{ 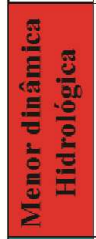 } & \multirow{4}{*}{$\begin{array}{l}\text { Alto Juruena } \\
\text { Médio Tapajós } \\
\text { Rio Jamaxim } \\
\text { Baixo Tapajós }\end{array}$} & $6^{\mathrm{a}}$ & 59.327 & 967 \\
\hline & & $7^{\mathrm{a}}$ & 58.997 & 760 \\
\hline & & $6^{\mathrm{a}}$ & 58.211 & 801 \\
\hline & & $7^{\mathrm{a}}$ & 42.686 & 752 \\
\hline \multirow{4}{*}{ 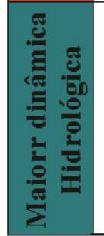 } & \multirow{4}{*}{$\begin{array}{c}\text { Rio do Sangue } \\
\text { Rio Arinos } \\
\text { Médio-Baixo Juruena } \\
\text { Teles Pires } \\
\end{array}$} & $5^{\mathrm{a}}$ & 28.945 & 607 \\
\hline & & $5^{\mathrm{a}}$ & 58.677 & 1155 \\
\hline & & $6^{\mathrm{a}}$ & 43.819 & 4465 \\
\hline & & $6^{\mathrm{a}}$ & 141.450 & 3947 \\
\hline
\end{tabular}

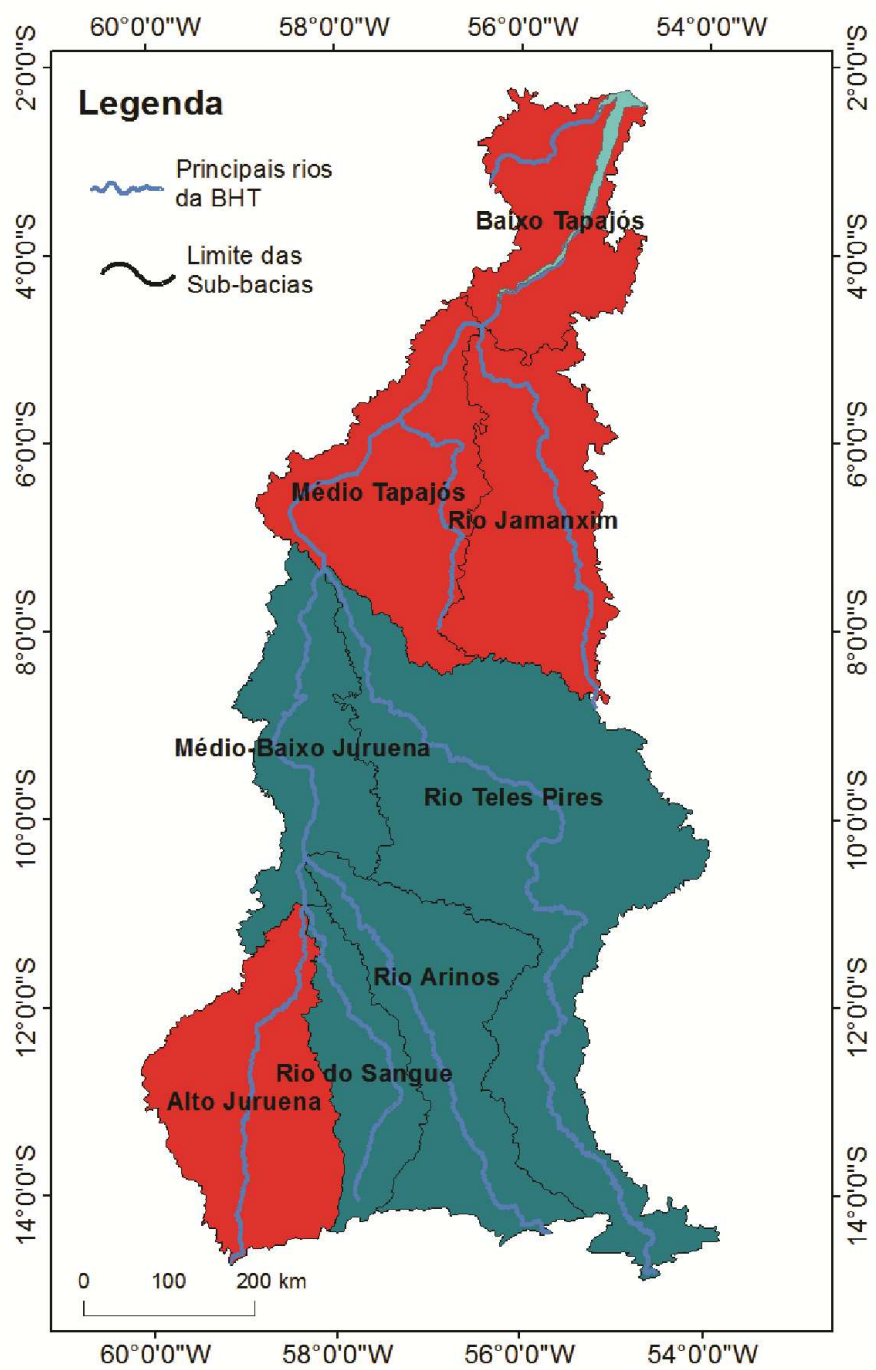

Sub-bacias da bacia hidrográfica do Tapajós

Fonte: Base vetorial dos dados hidrológicos elaborado pela ANA (Agência Nacional de águas), na escala de 1:250.000.

FIGURA 12. Representação das áreas com maior e menor dinâmica hidrológica no contexto das diferentes sub-bacias ao longo da BHT, bem como suas respectivas informações básicas quanto a hierarquia (ordem), área e número total de canais. Fonte: Autores. 
A região de MEDH é representada pela sub-bacia do Alto Juruena, próximo a nascente do rio Juruena, bem como a sub-bacias do rio Jamaxim, Médio Tapajós e Baixo Tapajós, no entorno do médio-baixo curso do rio Tapajós. Este comportamento no Alto Juruena está relacionado a dinâmica climática com maior estação seca ao longo da MEDH, como mostram SANTOS et al. (2014), bem como aos menores índices pluviométricos e de $\mathrm{Dd}$ na região. Nas sub-bacias do Rio Jamaxim, Médio Tapajós e Baixo Tapajós, além de apresentar baixos valores de Dd, nota-se também que em direção a foz do rio Tapajós os cursos de água escoam em uma direção preferencial, instalando-se em uma feição estrutural de gráben, como mostram COSTA et al. (2001), tornando assim os cursos menos dispersos e fazendo com que ação hidrológica interaja de forma mais local na paisagem (LANA \& CASTRO, 2012). Nas demais sub-bacias a ação hidrológica é mais intensa, apresentando assim maior dinâmica hidrológica tanto na intensidade dos processos erosivos quanto nas modificações provocadas nas formas de relevo, favorecendo assim os processos de dissecação (CHATANANTAVET et al. 2010; BATHURST, 2013).

Esse comportamento é expresso de forma gráfica na figura 11, onde os valores de $\mathrm{Dd}$, Ni e Tt são crescentes de MEDH para MADH. Os valores de Is são mais irregulares, contudo, nota-se que o valor mais baixo encontra-se em MEDH e o mais elevado em MADH. O If apresenta comportamento decrescente, onde os valores mais elevados estão associados as regiões com menor facilidade de escoamento da água, e possivelmente com menor dinâmica hidrológica; e os valores mais baixos estão relacionados as sub-bacias com maior facilidade ao escoamento de água, favorecendo assim a maior dinâmica hidrológica nas mesmas (WHITTAKER et al. 2010; ATTAL et al. 2015).

Dessa forma, as áreas com a maior e a menor dinâmica hidrológica ao longo de toda bacia estão apresentadas de forma esquemática na figura 12, bem como dados adicionais de cada sub-bacia analisada.

\section{Avaliação do comportamento hidrogeomorfológico}

Os processos de dissecação do relevo são os que ocorrem de forma mais expressiva na paisagem brasileira (IBGE, 2009.a). Como a ação hidrológica interage modificando o relevo e as modificações neste último influenciam também em mudanças nos cursos de drenagem (GOERL et al. 2012), a dinâmica hidrológica em uma bacia hidrográfica influencia diretamente na intensidade da dissecação das feições geomorfológicas. Dessa forma, a partir da análise integrada das UHs e a dinâmica hidrológica da BHT, nota-se que o comportamento hidrogeomorfológico da mesma pode ser expresso em dois grupos principais: zona mais e menos susceptível aos processos de dissecação nas formas de relevo (Figura 13). Cada zona diz respeito a áreas onde a dinâmica hidrológica atua de forma relativamente homogênea quanto aos processos de intensidade e modificação na paisagem no contexto das UHs.

A zona mais susceptível aos processos de dissecação do relevo (Zmas) ocupa, aproximadamente, $52 \%$ da BHT e diz respeito às UHs do Alto Teles Pires, Médio Juruena, Médio Teles Pires, Médio Baixo Juruena e o Baixo Juruena. Estas unidades possuem influência do médio e baixo curso dos rios Juruena e do Sangue, bem como o alto e baixo curso do rio Teles Pires e o curso do rio Arinos, que se encontram, predominantemente, em regiões altas a medianas dentro da bacia. 

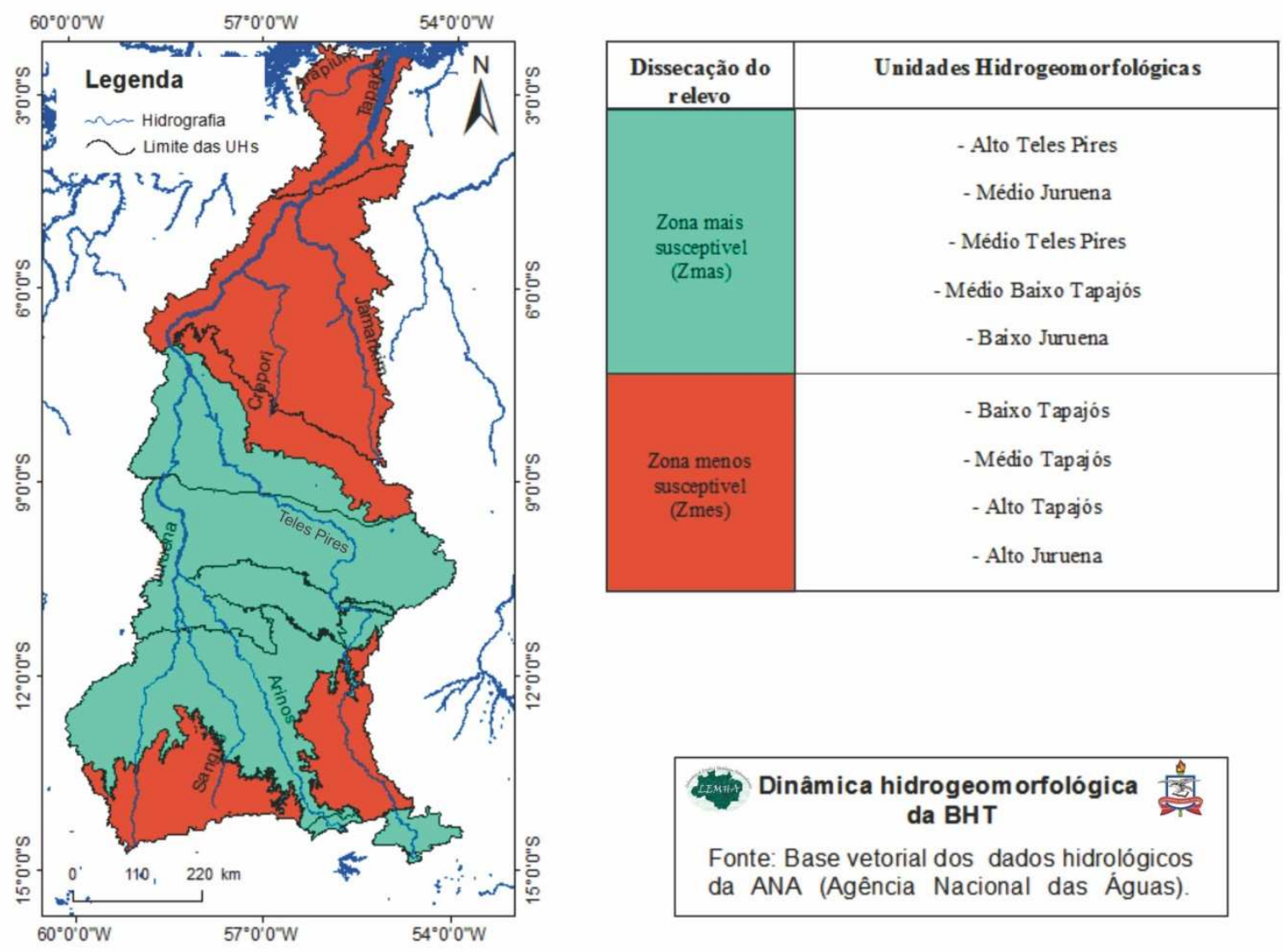

FIGURA 13. Comportamento hidrogeomorfológico da bacia do Tapajós frente a maior ou menor susceptibilidade quanto aos processos de dissecação do relevo. Fonte: Autores.

Apesar dos valores de vazão na cabeceira da BHT serem menores (SANTOS et al. 2015), o maior número de canais distribuídos ao longo da Zmas, bem como a litologia predominante presente na região contribuem para a maior modificação na paisagem frente à dinâmica hidrológica, favorecendo assim a maior erosão e retrabalhamento do relevo (LANA \& CASTRO, 2012; ATTAL et al. 2015). Todas as unidades dessa região, exceto a UH do Médio Baixo Juruena, são constituídas por rochas sedimentares mais susceptíveis a ação de agentes intempéricos, que favorecem a maior modificação na paisagem. As porções cristalinas, contudo, possuem alto número de infiltração no contexto da Zmas (sendo contrárias as condições esperadas de menor infiltração nesse tipo de rocha), atestando assim à presença de condicionantes que favoreçam a isso, como regiões intensamente fraturadas, já que a área apresenta influência estrutural do embasamento e/ou a presença de coberturas superficiais porosas.

Inserida, predominantemente, na área com menor média pluviométrica anual dentro da BHT (SANTOS et al. 2014), a área da Zmas apresenta variações no regime pluvial, onde no período de outubro a dezembro ocorre maior índice pluviométrico. Os valores de $\mathrm{Dd}$ e $\mathrm{Tt}$ na área de maior dinâmica hidrológica dentro da BHT corroboram também com a maior dissecação do relevo nas UHs presentes nessa região, já que os elevados valores desses parâmetros atestam o efeito do escoamento superficial da drenagem frente ao maior retrabalhamento dos componentes geomorfológicos (DAS et al., 2012). 
A zona menos susceptível aos processos de dissecação do relevo (Zmes), abrange em torno de $48 \%$ da $\mathrm{BHT}$, diz respeito às unidades na área de influência do rio Tapajós, nas regiões mais baixas de toda bacia, sendo representada pelas UHs do Baixo, Médio e Alto Tapajós; bem como a unidades mais alta de toda área de estudo, no entorno do alto curso dos rios Juruena e do Sangue, o Alto Juruena. Essas unidades possuem em comum baixa densidade de drenagem, predominantemente, bem como características hidrológicas, geológicas e/ou geomorfológicas que tornam os processos de dissecação do relevo a partir da ação da água menos intensos (LOLLO \& SENA, 2013; MACHADO \& CUNHA, 2013).

A UH do Médio Tapajós é constituída por um substrato mais resistente a ação da dinâmica hidrológica, composto por rochas cristalinas, que compõem, por vezes, relevos residuais, como os Planaltos Residuais do Sul do Pará. As demais unidades são compostas por rochas sedimentares, contudo, estas apresentam características que favorecem a menor modificação do relevo frente à dinâmica hidrológica. A região do Baixo Tapajós, próximo à foz do rio Tapajós, apesar de ter os maiores valores de vazão ao longo de toda bacia, apresenta menor número total de canais, bem como possui grande parte do seu volume de água concentrado no curso principal do rio Tapajós, diminuindo assim a área de interação dos cursos de água com a superfície.

As UHs do Alto Tapajós e do Alto Juruena são áreas topográficas mais elevadas, no entorno das Chapadas do Parecis e Cachimbó, respectivamente. Estas são regiões de nascentes que, posteriormente, desembocam no rio Tapajós. No entanto, a interação da dinâmica hidrológica com o relevo atua de forma pouco expressiva. O Alto Juruena, na sua porção leste, está inserido na região de maior dinâmica hidrológica ao longo da BHT (figura 12), no entanto, esta apresenta uma cobertura laterítica espessa que dificulta as modificações no relevo pela ação hidrológica, bem como ainda esta inserido na região de maior estresse hídrico da BHT (cabeceira do rio Juruena), como mostra SANTOS et al. (2014), conferindo assim menor ação pluvial nesta região.

No contexto da BHT, nota-se que na Zmas há maior contribuição de sedimentos inconsolidados em direção ao leito dos rios, ao longo da Planície Amazônica, favorecendo assim a formação de planícies de inundação. Na Zmes o aporte sedimentar em direção aos cursos é menos intenso em função da menor atuação da dinâmica hidrológica nesta região, que, influenciam diretamente, ao menor potencial a erosão das vertentes do relevo. A carga sedimentar presente no leito dos cursos nas regiões mais baixas de toda bacia são provenientes das unidades mais elevadas, já que as mesmas apresentam condições mais favoráveis aos processos de dissecação do relevo. Corroborando a isso, DANTAS \& TEIXEIRA (2013) afirmam que na porção sudoeste do estado do Pará a Planície Amazônica ocorre de forma restrita ao longo dos principais cursos de rios.

\section{CONCLUSÕES}

A partir da adoção da Bacia do Tapajós como unidade de análise, a metodologia utilizada se mostrou eficaz quanto à análise da paisagem natural, pois a compartimentação em Unidades Hidrogeomorfológicas auxilia na compreensão das regiões mais e menos susceptíveis aos processos de modificação e dissecação do relevo frente à dinâmica hidrológica da bacia, seja pela ação fluvial ou pluvial. No entanto, apesar da ação hidrológica, o contexto geológico e tectônico da região é o fator preponderante quanto aos aspectos estruturais do relevo, bem como nas direções preferenciais dos cursos de drenagem. 
Nota-se que o comportamento de Zmas e Zmes acompanha, de forma geral, às áreas de maior e menor dinâmica hidrológica da bacia do Tapajós. A Zmas predomina nas regiões mais elevadas, com declives baixos e médios ao longo de toda bacia, próxima a nascente dos rios Juruena, Sangue, Arinos e Teles Pires. A Zmes ocorre, predominantemente, nas porções mais baixas da bacia, na região de influência dos rios Tapajós, Crepori, Jamaxim e Aripiuns. Nestas áreas, apesar de estar na região com maior média pluviométrica anual e com os maiores declives na bacia, predominam rochas cristalinas. A unidade do Alto Juruena é a única exceção de Zmes nas regiões mais elevadas da bacia, tal fato se dá pela presença de uma crosta laterítica espessa. Dessa forma, em ambos os casos, os aspectos geológicos contribuem para a menor modificação do relevo frente à ação hidrológica na região.

Dessa forma, os resultados apresentados mostram extrema relevância por integrar uma grande quantidade de informações do meio físico da bacia, tal que a partir da importância da caracterização regional de bacias hidrográficas, a compartimentação em Unidades Hidrogeomorfológicas pode auxiliar no planejamento regional, contribuindo na avaliação de áreas mais e menos susceptíveis à ocorrência de processos erosivos e na elaboração de formas mais adequadas para uso e ocupação de uma região frente a uma determinada atividade de interesse, apresentando assim suma relevância no contexto das bacias hidrográficas amazônicas. Vale ressaltar a importância de estudos de campo em escala de detalhe para maior compreensão dos demais atributos que compõem a paisagem bem como para implantação de projetos com fins específicos.

\section{AGRADECIMENTOS}

A FAPESPA pelo suporte financeiro concedido ao desenvolvimento da pesquisa e ao Laboratório de Estudos e Modelagem Hidroambientais (LEMHA).

\section{REFERENCIAS}

ALVARENGA C, J. S.; TROMPETTE R. Evolução Tectônica brasiliana da Faixa Paraguai: a estruturação da região de Cuiabá. Revista Brasileira de Geociências, v. 32, n. 4, p. 18-30, 1993.

ATTAL, M.; MUDD, S. M.; HURST, M. D.; WEINMAN, B.; YOO, K.; NAYLOR, M. Impact of change in erosion rate and landscape steepness on hillslope and fluvial sediments grain size in the Feather River basin (Sierra Nevada, California). Earth Surface Dynamics, v. 3, p. 201-222, 2015.

BABAR, M. Hydrogeomorphological Analysis for Watershed Development In Jintur Tahsil, Parbhani Dist., Maharashtra. Indian Streams Research Journal, v. 1, n. 5, p. 168-173, 2011.

BATHURST, J. C. Critical conditions for particle motion in coarse bed materials of nonuniform size distribution. Geomorphology, v. 197, p. 170-184, 2013.

CARVALHO, A. P. V.; BRUMATTI, D. V.; DIAS, H. C. T. Importância do manejo da bacia hidrográfica e da determinação de processos hidrológicos. Revista Brasileira de Agropecuária Sustentável, v. 2, n. 2, p. 148-156, 2012. 
CHATANANTAVET, P.; LAJEUNESSE, E.; PARKER, G.; MALVERTI, L.; MEUNIER, $P$. Physically based model of downstream fining in bedrock streams with lateral input. Water Resource Research, v. 46, W02518, 2010.

CHEREM, L. F. S.; MAGALHÃES JÚNIOR, A. P.; FARIA, S. D. Análise e compartimentação morfométrica da bacia hidrográfica do Alto Rio das Velhas, região central de Minas Gerais. Revista Brasileira de Geomorfologia, v. 12, n. 1, p. 11-21, 2011.

CHRISTOFOLETTI, A. Geomorfologia. São Paulo-SP: Edgard Blücher, 1980, 188p. COSTA, J. B. S.; BEMERGUY, R. L.; HASUI, Y.; BORGES, M. S. Tectonics and paleogeography along the Amazon River. South American Earth Sciences, v. 14, p. 335-347, 2001.

COSTA, J. B. S.; BEMERGUY, R. L.; HASUI, Y.; BORGES, M. S.; FERREIRA JÚNIOR, C. R. P.; BEZERRA, P. E.; COSTA, M. L.; FERNANDES, J. M. G. Neotectônica da Região Amazônica: aspectos tectônicos, geomorfológicos e deposicionais. Geonomos, v. 4, n. 2, p. 23-44, 1996.

COUTINHO, L. M.; CECÍLIO, R. A.; XAVIER, A. L.; ZANETTI, S. S.; GARCIA, G. O. G. Caracterização morfométrica da bacia hidrográfica do rio da Prata, Castelo, ES. Irriga, v. 16, p. 369-381, 2011.

DANTAS, M. E.; TEIXEIRA, S. G. Origem das paisagens. In: JOÃO, X. S. J.; TEIXEIRA, S. G.; FONSECA, D. D. F. (org.), Geodiversidade do Pará. Programa Geologia do Brasil, Levantamento da Geodiversidade. Belém: CPRM - Serv. Geol. Brasil, p. 25-49, 2013.

DAS, A.; MONDAL, M.; DAS, B.; GHOSH, A. R. Analysis of drainage morphometry and watershed prioritization in Bandu Watershed, Purulia, West Bengal through Remote Sensing and GIS technology - A case study. International Journal of Geomatics and Geosciences, v. 2, n. 4, p. 995-1013, 2012.

DINIZ, N. C. Cartografia geotécnica por classificação de unidades de terreno e avaliação de suscetibilidade e aptidão. Revista Brasileira de Geologia de Engenharia e Ambiental, v. 2, n. 1, p. 29-77, 2012.

FILHO, J. V. L.; FILHO, W. A.; VELENTE C. R.; OLIVEIRA, C. C.; ALBUQUERQUE, M. C. (Org.). Geologia e recursos minerais do Estado de Mato Grosso: Programa integração, atualização e difusão de dados da geologia do Brasil, Subprograma mapas geológicos estaduais, escala 1:1.000.000. Goiânia: CPRM, 200 p., 2004.

FISHER, S. G.; HEFFERNAN, J. B.; SPONSELLER, R. A.; WELTER, J. R. Functional ecomorphology: Feedbacks between form and function in fluvial landscape ecosystems. Geomorphology, v. 89, n. 1-2, p. 84-86, 2007.

GIRÃO, O; CORRÊA, A. C. B. A contribuição da geomorfologia para o planejamento da ocupação de novas áreas. Revista de Geografia. v. 21, n. 2, p. 36-58, 2004. 
GOERL, R. F.; KOBIYAMA, M.; SANTOS, I. Hidrogeomorfologia: princípios, conceitos, processos e aplicações. Revista Brasileira de Geomorfologia, v. 13, n. 2, p. 103-111, 2012.

HUGGETT, R. J. Fundamentals of Geomorphology. Routledge: London, 2005, $386 p$.

IBGE. Manual técnico de geomorfologia. Rio de Janeiro: Instituto Brasileiro de Geografia e Estatística, n. 5, 2009.a., 182 p.

IBGE. Mapa geomorfológico no recorte da Amazônia Legal: Escala 1:250.000. CD-ROM, 2009.b.

IBGE. Mapa de Unidades do Relevo do Brasil: Escala 1:5.000.000. CD-ROM, 2006.

JADHAV, S. I.; BABAR, M. Linear and Aerial aspect of Basin morphometry of Kundka Sub-basin of Sindphana Basin (Beed), Maharashtra, India. International Journal of Geology, Agriculture and Environmental Sciences, v. 2, n. 3, p. 16-20, 2014.

LANA, C. E.; CASTRO, P. T. A. Níveis de base fluviais: síntese dos principais condicionantes e dinâmica de instalação. Brazilian Geographical Journal: Geosciences and Humanities research medium, v. 3, n. 1, p. 102-122, 2012.

LOLLO, J. A.; SENA, J. N. Establishing erosion susceptibility: analytical hierarchical process and traditional approaches. Bulletin Engineering Geology Environmental, v. 72, p. 589-600, 2013.

LOLLO, J. A.; VIVANCO, J. M. C.; CURTI, J. S. Collapse Susceptibility Mapping Using SRTM Data Obtained from Topodata Project. Engineering Geology for Society and Territory, v. 5. p. 885-891, 2015.

MACHADO, A. C. P.; CUNHA, C. M. L. A influência das características morfométricas do relevo na morfodinâmica: um estudo da alta bacia do rio Itanhaém/SP. Geociências, v. 32, n. 2, p. 298-316, 2013.

MACHADO, A. L.; PACHECO, J. B. Serviços ecossistêmicos e o ciclo hidrológico da Bacia Hidrográfica Amazônica - the biotic pump. Revista Geonorte, v. 1, n. 1, p. 7189, 2010.

PARETA, K.; PARETA, U. Quantitative geomorphological analysis of a watershed of Ravi River basin, H.P. India. International Journal of Remote Sensing and GIS, v. 1, n. 1, p. 41-56, 2012.

REIS, N. J.; RIKER, S. R. L.; PINHEIRO, S. S.; NOBRE, J. N.; CRUZ, N. M. C.; COSTI, H. T.Geologia dos rios Tapajós, Juruena (Bararati e São Tomé) e Teles Pires, porção sul do Cráton Amazônico, em área limítrofe dos estados do Amazonas, Pará e Mato Grosso. In: HORBE, A. M. C.; SOUZA, V. S. (Orgs.) Contribuição à Geologia da Amazônia. Manaus-AM: SBG/Núcleo Norte, v. 4, p. 55-68, 2006. 
ROSS, J. L. S. O registro cartográfico dos fatos geomórficos e a questão da taxonomia do relevo. Revista do Departamento de Geografia, v. 6, p. 17-29, 1992.

SANTOS, A. M.; TARGA, M. S.; BATISTA, G. T.; DIAS, N. W. Análise morfométrica das sub-bacias hidrográficas Perdizes e Fojo no município de Campos do Jordão, SP, Brasil. Revista Ambiente \& Água, v. 7, n. 3, p. 195-211, 2012.

SANTOS, C. A.; SERRÃO, E. A. O.; GONCALVES, L. J. M.; WANZELER, R. T. S.; LIMA, A. M. M. Zoneamento da distribuição da precipitação pluviométrica na bacia hidrográfica do rio tapajós. Enciclopédia Biosfera, v. 10, p. 3092-3106, 2014.

SANTOS, C. A.; ARAUJO, I. B.; WANZELER, R. T. S.; SERRÃO, E. A. O.; FARIAS, M. H. C. S.; LIMA, A. M. M. Regionalização hidroclimatológica da bacia hidrográfica do rio Tapajós. Revista Geográfica Acadêmica, v. 9, n. 1, p. 32-51, 2015.

SANTOS, J. M.; LIMA, K. C. Análise da Rede de Drenagem em Bacias Hidrográficas Tropicais: bacia do Riacho Grande - Bahia - Brasil. Geomorfologia, v. 6, p. 77-82, 2009.

SANTOS, J. O. S. Geotectônica dos Escudos das Guianas e Brasil-Central. In: BIZZI, L. A.; SCHOBBENHAUS, C; VIDOTTI, R. M.; GONÇALVES, J. H. (eds.), Geologia, Tectônica e Recursos Minerais do Brasil. Brasília: CPRM - Serv. Geol. Brasil, p. 169-226, 2003.

SCHEIDEGGER, A. E. Hydrogeomorphology. Journal of Hydrology, n. 20, p. 193215, 1973.

SILVA, E. R.; DELGADO, R. C.; SOUZA, L. P.; SILVA, I. S. Caracterização física em duas bacias hidrográficas do Alto Juruá, Acre. Revista Brasileira de Engenharia Agrícola e Ambiental, v. 18, n. 7, p. 714-719, 2014.

SOARES, P. C.; FIORI, A.P. Lógica e sistemática na análise e interpretação de fotografias aéreas em geologia. Notícia Geomorfológica, v. 16, n. 32, p. 71-104, 1976.

STRALHER, A. N. Hypsometric (area-altitude) analysis of erosional topography. Geol. Soc. America Bulletin, v. 63, p. 1117-1142, 1952.

TEODORO V. L. I.; TEIXEIRA, D.; COSTA, D. J. L.; FULLER, B. B. O conceito de bacia hidrográfica e a importância da caracterização morfométrica para 0 entendimento da dinâmica ambiental local. Revista Uniara, v. 20, p. 137-157, 2007.

VALENTIM, R. F.; OLIVITO. J. P. R. Unidade espeleológica Carajás: delimitações dos enfoques regional e local, conforme metodologia da IN- 02/2009 MMA. Revista Espeleo-Tema, v. 22, n. 1, p. 41-60, 2011.

VALERIANO, M. M.; CARVALHO JÚNIOR, O. A. Geoprocessamento de modelos digitais de elevação para mapeamento da curvatura horizontal em microbacias. Revista Brasileira de Geomorfologia, v. 4, n. 1, p. 17-29, 2003. 
VASQUEZ, M. L.; ROSA-COSTA, L. T. Geologia e recursos minerais do estado do Pará - SIG: texto explicativo dos mapas geológico e tectônico e de recursos minerais do estado do Pará, Belém-PA: CPRM, 2008, 329p.

VASQUEZ, M. L.; SOUSA, C. S.; CARVALHO, J. M. A. (Orgs.). Mapa Geológico e de Recursos Minerais do Estado do Pará: escala 1:1.000.000. Belém-PA: CPRMServ. Geol. Brasil, CD-ROM, 2008.

WHITTAKER, A. C.; ATTAL, M.; ALLEN, P. A. Characterizing the origin, nature and fate of sediment exported from catchments perturbed by active tectonics, Basin Research, v. 22, p. 809-828, 2010. 